\title{
Structuring a fecal microbiota transplantation center in a university hospital in Brazil
}

\author{
Daniel Antônio de Albuquerque TERRA ${ }^{1}$, Eduardo Garcia VILELA ${ }^{1}$, \\ Rodrigo Otávio Silveira SILVA² ${ }^{2}$ Laiane Alves LEÃ ${ }^{1}$, Karine Sampaio LIMA' ${ }^{1}$, \\ Raissa Iglesias Fernandes Ângelo PASSOS ${ }^{1}$, Amanda Nádia DINIZ² and Luiz Gonzaga Vaz COELHO1
}

Received: 28 May 2020

Accepted: 30 June 2020

\begin{abstract}
Background - Fecal microbiota transplantation (FMT) is an important therapeutic option for recurrent or refractory Clostridioides difficile infection, being a safe and effective method. Initial results suggest that FMT also plays an important role in other conditions whose pathogenesis involves alteration of the intestinal microbiota. However, its systematized use is not widespread, especially in Brazil. In the last decade, multiple reports and several cases emerged using different protocols for FMT, without standardization of methods and with variable response rates. In Brazil, few isolated cases of FMT have been reported without the implantation of a Fecal Microbiota Transplantation Center (FMTC). Objective - The main objective of this study is to describe the process of implanting a FMTC with a stool bank, in a Brazilian university hospital for treatment of recurrent and refractory C. difficile infection. Methods - The center was structured within the criteria required by international organizations such as the Food and Drug Administration, the European Fecal Microbiota Transplant Group and in line with national epidemiological and regulatory aspects. Results - A whole platform involved in structuring a transplant center with stool bank was established. The criteria for donor selection, processing and storage of samples, handling of recipients before and after the procedure, routes of administration, short and long-term follow-up of transplant patients were determined. Donor selection was conducted in three stages: pre-screening, clinical evaluation and laboratory screening. Most of the candidates were excluded in the first (75.4\%) and second stage $(72.7 \%)$. The main clinical exclusion criteria were: recent acute diarrhea, overweight (body mass index $\geq 25 \mathrm{~kg} / \mathrm{m}^{2}$ ) and chronic gastrointestinal disorders. Four of the 134 candidates were selected after full screening, with a donor detection rate of $3 \%$. Conclusion - The implantation of a transplant center, unprecedented in our country, allows the access of patients with recurrent or refractory $C$. difficile infection to innovative, safe treatment, with a high success rate and little available in Brazil. Proper selection of qualified donors is vital in the process of implementing a FMTC. The rigorous clinical evaluation of donors allowed the rational use of resources. A transplant center enables treatment on demand, on a larger scale, less personalized, with more security and traceability. This protocol provides subsidies for conducting FMT in emerging countries.
\end{abstract}

HEADINGS - Fecal microbiota transplantation. Clostridium infections. Microbiota. Gastrointestinal microbiome. Diarrhea. Feces.

\section{INTRODUCTION}

\section{Human gut microbiota}

The gut microbiota is one of the most complex systems in the human body. It consists of $10^{14}$ microorganisms and participates in important health functions such as digestion, immunity, vitamin synthesis, carbohydrate fermentation and bile metabolism ${ }^{(1,2)}$. When in balance, it plays an important role in resisting colonization of external pathogens. It develops from birth in a dynamic process, influenced by genetic and environmental factors such as way of delivery, breastfeeding, used medications, geographic location and lifestyle. From the age of three, microbiota becomes more stable, with less inter-individual variability, and remains so throughout adulthood. However, they do not maintain their composition in a fixed way and can change in response to environmental stimuli and factors of the host itself. It is considered as a metabolically active organ, composed of a number of organisms ten times greater than the number of cells in the human body and capable of exercising its function in the intestinal and extra-intestinal systems ${ }^{(1)}$.
In human feces, enteric microorganisms correspond to almost half of solid portion ${ }^{(3)}$. In addition to bacteria that are present in number of $10^{11}$ per gram of dry feces, there are viruses in number of $10^{8}$ per gram of feces, archaea $\left(10^{8}\right.$ per gram of feces), colonocytes $\left(10^{7}\right.$ per gram of feces), fungi $\left(10^{6}\right.$ per gram of feces) and, yet protozoa, metabolites and genetic material, that compounds minority of $\mathrm{it}^{\mathrm{t}^{(3)}}$. Each component acts synergistically to maintain local homeostasis between the microbiome and the host. Even bacterial deoxyribonucleic acid (DNA) and dead cells have an immunostimulating and environmental balancing function.

Human microbiota knowledge has grown rapidly and has provided important discoveries. Through genetic sequencing techniques it is now possible to better characterize and study its changes in different situations and diseases ${ }^{(2)}$. The resulting disorder of its homeostasis, known as dysbiosis, has been related to several diseases pathogenesis, i.e. Clostridioides difficile infection (CDI), which has being the most studied affection. In this way, there is a progressive effort in the development of new therapies capable of modulating the microbiota, correcting dysbiosis and promoting

1 Instituto Alfa de Gastroenterologia, Hospital das Clínicas / EBSERH, Universidade Federal de Mina Gerais, Belo Horizonte, MG, Brasil. ${ }^{2}$ Universidade Federal de Minas Gerais Escola de 
advances in the treatment of these conditions. Among the possibilities of microbiota modulation, the use of prebiotics, symbiotics, probiotics and, more recently, the fecal microbiota transplantation (FMT) stands out.

\section{Fecal microbiota transplantation}

FMT is the procedure in which microbiota from healthy donors is transferred to the gastrointestinal tract of a sick person in order to repopulate their digestive tract, correcting underlying dysbiosis and promoting patient's recovery process. Unlike probiotics, the material introduced is composed of all diversity of species present in the donor's feces and capable of exercising its functions for an extended period ${ }^{(4)}$. FMT can be performed using various methods such as oral pills, nasogastric tubes, nasoenteric tubes and enemas or during endoscopic or colonoscopic procedures. There is, to date, no study that indicates the superiority of one over another ${ }^{(5)}$.

\section{- History of fecal microbiota transplantation}

Despite the enthusiasm in modern medicine, the use of healthy stools to treat sick people has been described since antiquity ${ }^{(6)}$. The first records on fecal transplantation date back to the fourth century in China. During the Dong Jin dynasty, physician Ge Hong first described, in his medical manual "Zhou Hou Bei Ji Fang", the ingestion of human fecal suspension for the treatment of food poisoning and severe diarrhea. Later, in the 16th century, the physician Li Shizhen documented in his traditional medicine book "Ben Cao Gang Mu" the use of dry stools, fermented fecal suspensions, and even fresh children's feces for the treatment of severe diarrhea, fever, vomiting, and intestinal constipation. For better acceptance, this treatment was called "yellow soup" or "golden syrup"(6).

During World War II, German soldiers in Africa (Afrika Korps) were told to use camel feces to treat bacterial dysentery. While many soldiers died of dysentery, the local population protected themselves by consuming fresh, warm camel feces at the first sign of illness. From this observation, Nazi scientists analyzed the feces and managed to isolate Bacillus subtilis, used later by the corporation with good results ${ }^{(7)}$.

The first description of FMT in modern medicine dates back to 1958 . Ben Eiseman successfully used fecal enemas to treat four patients with severe pseudomembranous colitis refractory to the use of antibiotics ${ }^{(8)}$. Even without microbiological confirmation, patients probably would have CDI.

In 2013, the first randomized clinical trial using FMT to treat recurrent CDI was published ${ }^{(9)}$. Patients were randomized to receive one of three therapies: (1) oral vancomycin $500 \mathrm{mg}$ every $6 \mathrm{~h}$ for four days followed by intestinal lavage and subsequent FMT using nasoenteric tube; (2) therapy with isolated oral vancomycin ( $500 \mathrm{mg} 6 / 6 \mathrm{~h}$ orally for 14 days) or (3) therapy with oral vancomycin plus intestinal lavage. The study had to be stopped after the initial analysis of the data, given the high effectiveness of FMT. Of the 16 patients in the FMT group, 13 (81\%) had resolution of the diarrhea after the first infusion. The resolution of diarrhea in the group of vancomycin alone and vancomycin with intestinal lavage was $31 \%$ and $23 \%$, respectively $(P<0.001)$. FMT was significantly more effective than standard treatment. From this randomized clinical trial, the effectiveness of FMT has been proven by other studies. Currently, FMT has become standard therapy for recurrent CDI and is currently under investigation for the treatment of other diseases.

\section{Indications for fecal microbiota transplantation}

FMT has established itself as a promising therapy for CDI cases and has changed concepts about the management of these patients, specifically in the prevention of new recurrences. Based on case series, randomized clinical trials and meta-analyzes, the European Consensus on Fecal Microbiota Transplantation, Australian Consensus for Transplantation in Clinical Practice and American Society of Infectious Diseases decided to recommend FMT as treatment for refractory or recurrent CDI, especially from of the second recurrence episode ${ }^{(10-12)}$. There is not enough data to recommend it as treatment for the first episode, or as an adjunct to antibiotic therapy ${ }^{(12)}$. Marie Hocquart et al. have proposed that FMT should be considered a first-line treatment for severe cases of CDI, based on the significant reduction in three months mortality rate ${ }^{(13)}$. However, further studies are needed to make this proposal consensual.

There are several conditions in which FMT has been tested as a therapeutic option, although still on an experimental basis. Among them, it has been evaluated in inflammatory bowel disease, irritable bowel syndrome, obesity, peripheral insulin resistance, hepatobiliary disorders, hemato-oncological diseases, infections by resistant multidrug organisms and neurological syndromes ${ }^{(14)}$. However, the recurrent or refractory CDI represents the main indication for transplantation, considering the volume and strength of the evidences ${ }^{(11,12)}$. The effectiveness is around $90 \%$ in treating recurrent CDI and it is associated with few side effects, mostly mild and transient $t^{(9,15-18)}$. Beside this, it improves quality of life and is well accepted by patients ${ }^{(19)}$. Nevertheless, a minority of cases do not respond satisfactorily. Factors related to donors, recipients, and the procedure itself can contribute to treatment failure and require investigation. Elements that can negatively influence the result of the transplant include low stool volume, severe colitis, colitis with endoscopic evidence of pseudomembranes, concomitant use of other antibiotics, and hospitalization ${ }^{(11,12)}$.

Ideally, it is necessary to structure transplantation centers and stool banks, capable of supplying material and carrying out the procedure in an agile and safe manner. Aware of the growing implantation of fecal transplantation centers, the Food and Drug Administration (FDA), in 2013, regulated FMT as a new treatment modality and established recommendations for the procedure ${ }^{(20)}$. In the same year, the Infectious Diseases Society of America (IDSA), American Society for Gastrointestinal Endoscopy (ASGE), North American Society for Pediatric Gastroenterology, Hepatology and Nutrition (NASPGHAN), American Gastroenterological Association (AGA) and American College of Gastroenterology (AGC) have issued consensual guidelines to regulate the screening and analysis of donor feces ${ }^{(21)}$.

The current recommendation is that the FMT be performed in reference centers for the treatment of CDI, especially in hospitals with experience in the treatment of $C$. difficile and appropriate logis$\operatorname{tics}^{(12,22)}$. The center must be composed of a multidisciplinary team led by a gastroenterologist, microbiologist or infectious disease physician, with appropriate scientific knowledge and experience with FMT. The director of the bank must ensure that the supply of fecal samples in clinical practice is only for CDI patients. For others indications, it is necessary perform research protocols and approve these by the local ethics committee under rigorous review ${ }^{(22)}$. The stool bank must also have the participation of a biobank specialist capable of processing and storing the samples under standardized conditions and ensure compliance with quality standards required in the process ${ }^{(22)}$. 


\section{- Recurrent or refractory C. difficile infection}

The Clostridium difficile had its nomenclature recently changed and was renamed to Clostridioides difficile $e^{(23)}$. It represents the main pathogen responsible for diarrhea associated with human health care. It is a Gram-positive, spore-forming bacillus whose toxins cause gastrointestinal disease with a wide spectrum of severity. The clinical presentation ranges from mild diarrhea, pseudomembranous colitis to toxic megacolon, which can lead to death. Its incidence, severity and recurrence have increased worldwide over the last decades ${ }^{(24)}$. The indiscriminate use of antibiotics, especially quinolones, longevity of the population, and appearance of hypervirulent strains, responsible for major epidemics around the world, has contributed to the increase in morbidity and mortality associated with $\mathrm{CDI}^{(25)}$. The mortality rate in the United States increased from $1.5 \%$ to $6 \%$, reaching $17 \%$ in periods of epidemic ${ }^{(24)}$. In cases of severe CDI, mortality is around $36 \%-58 \% 0^{(26,27)}$. The infection is usually treated with antibiotics such as metronidazole, vancomycin or fidaxomicin, and has a recurrence rate of $25 \%-30 \%{ }^{(28)}$. More than that, patients who have subsequent relapses have a chance of developing a new recurrence of up to $60 \%$, even when adequately treated with antibiotics ${ }^{(28)}$. The pathophysiological basis for this behavior is not restricted to the existence of antimicrobial resistance, but rather to the inability to reestablish a healthy intestinal microbiota that prevents the development of the new infection ${ }^{(29)}$.

The mechanism involved in the recurrence is the re-exposure or reactivation of $C$. difficile spores in patients with deficient immune response associated with defect in the colonic epithelial barrier function and dysbiosis ${ }^{(30)}$. Patients with recurrent CDI have a reduced diversity of microbiota, usually secondary to prior antibiotics exposure used to treat others conditions or even to treat $\mathrm{CDI}^{(31)}$. The traditional antibiotic therapy used in CDI can generate a dysbiosis cycle by perpetuating the imbalance of the microbiota favoring a propitious environment to the proliferation of $C$. difficile. The exact mechanism of action of FMT has not yet been fully elucidated, but the rationale for the transplant is that it is able to break the cycle of dysbiosis by introducing a new healthy microbiota, characteristically rich in diversity, capable to occupy the intestinal niche and prevent development of $C$. difficile. However, the microbiota is not the unique determinant for the therapeutic success of FMT. Study conducted by Ott et al., in 2017 showed that transplantation with filtered and sterile fecal substrate, free of viable bacteria, is also effective in the treatment against recurrent $\mathrm{CDI}^{(32)}$. This finding suggests that non-bacterial substances such as proteins, antimicrobial compounds, metabolic products and oligonucleotides also contribute to the therapeutic effect of FMT.

\section{C. difficile infection scenario and fecal microbiota transplantation in Brazil}

In Brazil, CDI is recognized as the main cause of nosocomial diarrhea related to the use of antibiotics ${ }^{(33)}$. Despite underreporting and few national epidemiological data, the number of records on isolation and characterization of $C$. difficile in our country is growing. Cançado et al., in 2018, evaluated a cohort of adults admitted to a university hospital in Belo Horizonte who developed diarrhea after the use of antibiotics. The prevalence of CDI was $31.8 \%$ and was related to underlying comorbidities and the number of antibiotics used during hospitalization. Almost all of the toxigenic strains had the tcdA or tcdB genes. The main PCR ribotypes identified were 014/020 and 106. Binary toxin-producing strains not associated with ribotypes 027 and 078 have also been identified ${ }^{(34)}$.
In the same year, in Brazil, the hypervirulent ribotype $027 C$. difficile strain (NAP1 / 027) was isolated for the first time ${ }^{(35)}$. This strain was responsible for the increase in worldwide cases of CDI since 2000, including outbreaks in North America and Europe ${ }^{(33)}$. This more virulent ribotype had already been isolated in Australia, Asia, Central America and South America, but not yet in Brazil. However, despite the lack of reports of national outbreaks to date, the identification of the new hypervirulent ribotype $027 \mathrm{C}$. difficile strain and other strains producing binary toxin in the country raises the alert for the need to optimize preventive measures, disseminate diagnostic methods and improve access to therapeutic measures, in particular, FMT.

Despite the advent of recurrent CDI cases in Brazil, FMT is still not a reality in Brazilian clinical practice. There are few reports of fecal transplantation in our country. So, as far as we know, only one study has been fully published in 2015, describing the experience of 12 patients with CDI undergoing transplantation in São Paulo city, with a success rate of $90 \%{ }^{(36)}$. In all these cases, the procedure was not performed from a stool bank, a premise for structuring a fecal microbiota transplantation center based on international recommendations. In addition, there is a paucity of data on donor screening in emerging countries, especially in Brazil.

\section{Regulatory aspects about fecal microbiota transplantation and stool bank}

In the United States, in May 2013, the FDA regulated FMT as a new therapy under investigation (US Investigational New Drug, IND) ${ }^{(20)}$. This decision was received with some concern by the medical community and by patients as it could limit access to a promising treatment modality. Later, in July 2013, the agency changed its previous declaration, releasing patients with recurrent CDI from the need to apply IND, since the informed consent form (IC) has been signed ${ }^{(21)}$. The term should explain that FMT is a treatment under investigation. It should address risks, benefits and alternative treatments. The donor and feces must pass screening tests carried out by the suitably qualified service provider ${ }^{(20)}$. The release did not include the other indications for transplant. To perform the FMT for other conditions, it is necessary for institutions to send an IND request.

In Europe, in December 2014, the European Commission considered the feces used in the transplant as a "combined product", composed of human cells and non-human components, such as the microbiome ${ }^{(37)}$. However, considering that the human component is not primarily responsible for the therapeutic response of FMT, the commission decided that the fecal substrate would not criteria to the guidelines of the European Tissue and Cells Directive (ETCD). The competent authorities have therefore allowed the regulation to be managed at national implementing level. Member states would be free to create specific regulatory structures for the transplantation in their territories and each stool bank must operate under the regulations of each country.

In Brazil, as well as in several countries in the world, there are no specific regulations for FMT. The International Consensus on Fecal Microbiota Transplant recommends that, in the absence of local guidelines, the transplant be performed under the aegis of a stool bank with a responsible scientific committee ${ }^{(22)}$. The bank must have a doctor to evaluate, select and recruit stool donors; microbiologist and /or pharmacist to coordinate all procedures related to stool processing and storage; a biobanks specialist to properly store fecal samples and a staff to ensure compliance with 
all steps. As it is a treatment under investigation, it is recommended that FMT be performed along the standards of a scientific study. According to the legislation that rules studies involving human beings, prior approval of the research protocol by the institution's Research Ethics Committee is required.

\section{OBJECTIVE}

\section{General objective}

To implement a fecal microbiota transplantation center with stool bank in a Brazilian university hospital for the treatment of patients with recurrent or refractory CDI, qualified for regional and national cases.

\section{Specific objectives}

- To describe the process of structuring the fecal microbiota transplant center with a frozen stool bank.

- To define donor selection protocol.

- To establish procedure for preparation and storage of fecal samples.

- To determine procedures for administration of fecal substrate.

- To create a platform for future studies in the field of intestinal microbiota.

\section{METHODS}

Infrastructure of the fecal microbiota transplantation center

The Fecal Microbiota Transplant Center (FMTC) was structured within Tumors and Tissues Bank of the Instituto Alfa de Gastroenterologia, Hospital das Clínicas, Universidade Federal de Minas Gerais (UFMG) / Empresa Brasileira de Serviços Hospitalares (EBSERH) (IAG-HC/UFMG), and developed within the required criteria approved by international organizations such as the FDA, European Fecal Microbiota Transplant Group and in accordance with national regulatory aspects. In this process, it had the partnership of the Bacteriosis Laboratory, Department of Preventive Veterinary Medicine, Escola de Veterinária UFMG and the Endoscopy Unit, IAG-HC/UFMG. FMTC is formed by a multidisciplinary team involving gastroenterologists, endoscopists, microbiologists, biomedicals, and pharmacists with experience in CDI, biobank, and donor and recipient procedures in human biological materials. FMTC and Tumors and Tissues Bank IAG-HC/UFMG have been approved by the Research Ethics Committee of the Federal University of Minas Gerais (CAAE
72755217.8.0000.5149 - opinion 2.264.667 on September 8, 2017) and by National Commission for Research Ethics, respectively.

\section{Study design}

This work was divided into two stages. Firstly, a literature review was carried out on relevant aspects in the structuring of FMTC with a frozen stool bank. Articles linked to electronic banks PubMed, Lilacs, MEDLINE and Cochrane were searched and selected according to title, summary and relevance in the field of FMT. The main descriptors were Clostridium difficile (currently, renamed to Clostridioides difficile), recurrent Clostridium difficile infection, fecal microbiota transplantation, fecal transplantation, intestinal microbiota transplantation, donor selection, frozen stool and stool bank. The search was limited to studies published in English and Portuguese until September 2019. At the same time, meetings were held to outline protocols, carry out a standard operating procedure, review and analyze the measures already in place and define new guidelines. Donors were selected and the methodology was used to prepare and store the fecal substrate. After acquiring the first samples, the functioning of the FMTC was publicized in state and national media such as TV news, radios, magazines and social networks of the Brazilian Federation of Gastroenterology and the Minas Gerais Gastroenterology Association.

The second stage of the study consisted of conducting a prospective, open, uncontrolled pilot study, in a single center, to evaluate the effectiveness of fecal microbiota transplantation in patients with recurrent or refractory CDI. Patients received the transplant from healthy donors selected in the first stage. Clinical and demographic variables, comorbidities, previous exposures to medications, severity of CDI and laboratory data of ten patients before and after treatment were evaluated. The aim was to report the initial experience with transplants and to determine the resolution rate and safety in short and long term. This stage is part of another study and is not included in this publication.

\section{Donor selection}

The donor selection was carried out prospectively in a threestep approach: (1) recruitment and pre-screening; (2) clinical assessment, and (3) laboratory screening with blood and stool tests (FIGURE 1). The selection criteria were conducted according to consensus recommendations among the protocols as well as Brazilian epidemiological specificities. The recommended criteria came from FMT Working Group, Amsterdam protocol, Australian
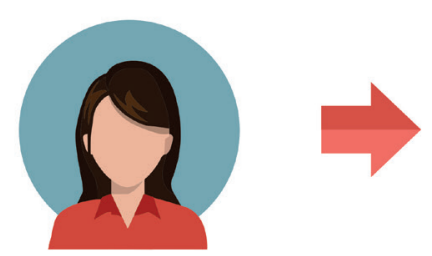

STAGE 1

Recruitment and pre-screening
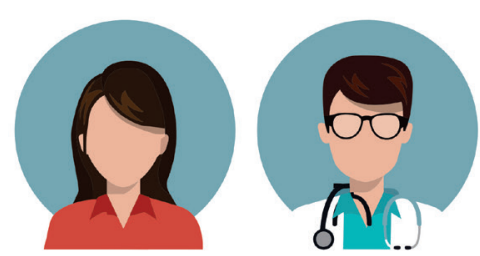

STAGE 2

Clinical assessment

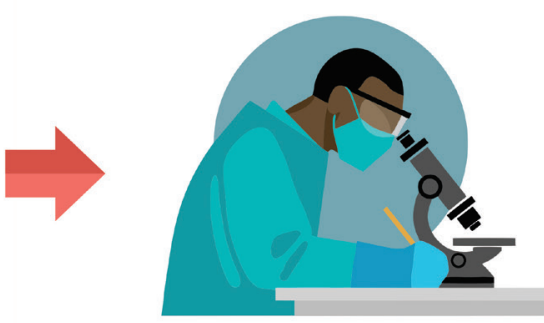

STAGE 3

FIGURE 1. Steps in the process of selecting stool donors. 
protocol, the consensual guidelines in the letter from American societies to the FDA, European Consensus on FMT, International Consensus on Stool Banking for FMT and OpenBiome ${ }^{(9,12,22,38-41)}$.

\section{- Recruitment and pre-screening}

Volunteers were screened for eligibility assessment as fecal donors. Candidates received an invitation to voluntary participation and underwent a self-assessment that addressed four issues: (1) presence of a known disease; (2) body overweight; (3) recurrent digestive complaints and, (4) logistical unavailability for stool donation. The presence of at least one of these criteria made it impossible to continue the donor selection process. Those approved passed to the second stage as potential donors.

\section{- Clinical evaluation of potential donors}

The clinical evaluation was performed by a single researcher and consisted of a complete medical interview, with details on health history, physical examination and analysis of inclusion and exclusion criteria. The candidates were submitted to a questionnaire similar to the one used in blood donation. Only donors approved at this stage were subjected to blood and stool tests.

\section{- Laboratory evaluation of potential donors}

Blood and stool tests for potential fecal donors are detailed in FIGURE 2 and FIGURE 3 respectively.

\section{- Donor inclusion criteria}

Adult individuals, of both sexes, related or not to the recipient, aged between 18 and 50 years old and who agreed to the process of selection and donation of feces by signing the informed consent form.

\section{- Donor exclusion criteria}

Donor exclusion criteria are detailed in FIGURE 4

\section{General blood tests}

\begin{tabular}{l|l} 
Complete blood count & Aspartate aminotransferase \\
C-reactive protein & Alanine aminotransferase \\
Urea & Gamma glutamyl transferase \\
Creatinine & Bilirubins \\
Sodium & Alkaline phosphatase \\
Potassium & Albumin \\
Chlorine & Prothrombin time \\
Magnesium & Partial thromboplastin time \\
Calcium & Total cholesterol and fractions \\
Glucose & Triglycerides \\
25-hydroxyvitamin D & Thyroid-stimulating hormone \\
Folic acid & Free T4 \\
Vitamin B12 &
\end{tabular}

Serological tests

Syphilis (VDRL)
Hepatitis A, B and C (antibody test)
HIV 1 and 2 (combined antibody and antigen test)
HTLV 1 and 2 (antibody test)
Chagas disease (antibody test with two combined methods: hemagglutination and
indirect immunofluorescence)
Schistosomiasis (antibody research)

FIGURE 2. Blood testing for potential fecal donors.

VDRL: venereal disease research laboratory; HIV: human immunodeficiency virus; HTLV: human T-lymphotropic virus.

Bacterial tests

C. difficile (GDH and toxigenic culture)

Enteric pathogens: Salmonella sp., Shigella sp., Campylobacter sp., Vibrio cholerae, Yersinia sp. (culture)

Escherichia coli 0157 (isolation and PCR)

Salmonella sp. (isolation and PCR)

Clostridium perfringens (isolation and PCR)

Campylobacter sp. (PCR)

MRSA, VRE, ESBL-producing enterobacteria and carbapenemaseproducing enterobacteria (culture)
Parasitic tests

Viral tests

\begin{tabular}{l|l} 
Microscopy for eggs and parasites in three serial & Norovirus (PCR) \\
samples & Rotavirus (PCR) \\
Giardia lamblia (microscopy and antigen) & Coronavirus (PCR) \\
Strongyloides stercoralis (microscopy and & \\
Baermann-Moraes method) & \\
Entamoeba histolytica (microscopy and antigen) & \\
Schistossoma mansoni (microscopy) & \\
Isospora (microscopy) & \\
Microscoridia (microscopy) &
\end{tabular}

FIGURE 3. Stool testing for potential fecal donors.

GDH: glutamate dehydrogenase; PCR: polymerase chain reaction; MRSA: methicillin-resistant Staphylococcus aureus; VRE: vancomycin-resistant enterococci; ESBL: expanded-spectrum beta-lactamase. 
- Fever of unknown origin or fever in the last 2 weeks or active infection not controlled during donation.

- Exposure to antibiotics, immunosuppressants or chemotherapy in the last 3 months.

- Active communicable disease (HIV, hepatitis A, B or C).

- Known exposure or previous history of HIV 1 and 2 , hepatitis $B$, hepatitis $C$, syphilis, HTLV 1 and 2, malaria, Chagas disease, tuberculosis, cutaneous and mucous herpes.

- History of gastrointestinal complaints or diseases, including inflammatory bowel disease, irritable bowel syndrome, celiac disease, diarrhea or chronic intestinal constipation, gastrointestinal malignancies, polypoid syndromes, excess of gas, flatulence or major gastrointestinal surgical procedures.

- Previous history of organ and tissue transplantation (including cornea).

- History of blood transfusion in the last 6 months.

- History of biological accident with sharp-edged objects in the last 6 months.

- Recent history (last 2 months) of vaccination with live attenuated virus.

- History of autoimmune, atopic diseases or ongoing immunomodulatory therapy.

- Risk factors for Creutzfeldt-Jacob disease (previous or family history, graft recipients such as corneal transplant, previous use of cadaveric pituitary hormones, previous use of bovine insulin, nosocomial exposure, people who remained in the United Kingdom and/or Ireland for more than three months between 1980 and 1996 or who have stayed for more than five years, consecutive or intermittent, in Europe after 1980 to the present day).

- Health professionals exposed to the risk of transmitting infectious diseases or the risk of being carriers of multidrug-resistant organisms.

- Professionals who work with animals, at risk of transmission of zoonoses.

- High-risk sexual behavior (sexual contact with anonymous people, sexual contact with sex workers, drug use before sexual intercourse, sexual contact with individuals with HIV or viral hepatitis, man who has sex with man, relationship with bisexual man, multiple partners sexual and sex workers).

- New sexual contact in the last 12 months.

- Previous history of sexually transmitted disease.

- Use of intravenous or inhaled illicit drugs.

- Recent history of hospitalization (for more than 2 days in the last 3 months), incarceration or stay in long-term health institutions.

- Implant of piercing, earrings, tattoos, or acupuncture in the last 6 months.

- Recent history of hematochezia or other bleeding from the gastrointestinal tract (last 2 months).

- Recent acute diarrheal disease in the last 6 months.

- Overweight and obesity defined by the World Health Organization as a body mass index (BMI) greater than or equal to 25 and $30 \mathrm{~kg} / \mathrm{m}^{2}$ respectively.

- Moderate to severe malnutrition.

- Diabetes mellitus, metabolic syndrome.

- Psychiatric disorders; chronic pain syndromes (fibromyalgia, chronic fatigue) or neurological syndromes.

- History of malignant neoplasms.

- Chronic use of proton pump inhibitors (for at least 3 months).

- Family history of polypoid syndrome or premature colorectal cancer (under 50 years old) in a first-degree relative.

- Detection of any changes in blood tests or stool tests.

FIGURE 4. Diseases or conditions that permanently or transitively excluded a potential donor.

\section{Fecal substrate collection}

Donors were requested to do weekly collections in the first month and every 15 days for the next three months. At the time of feces collection, donors were evaluated on their health conditions since the last screening. Telephone contact was made with each donation to address the following risk factors: (1) development of diarrhea; (2) presence of any disease or complaint; (3) use of antibiotics or new drugs; (4) new sexual contact. Donors with symptoms of active infection or one of the risk factors mentioned above were temporarily excluded. After the period defined in the exclusion criteria (six months for diarrhea, three months for antibiotics, 12 months for new sexual contact), the candidate was summoned and, if they agreed, submitted to a new screening process.

The collections were performed during four months after approval in the donor selection process. After this period, the donor was invited to remain in the program. For this, it was necessary to undergo a new screening with a complete clinical evaluation, blood and fecal exams.

The donated feces were collected in routine examination vials ( $50 \mathrm{~mL} / 50 \mathrm{~g}$ of feces) according to the standard stool collection procedure, on a clean and dry plastic surface and at home. The material identified with the donor's name, date and time of collection was sent to the FMTC laboratory within two hours. The professional responsible for receiving and preparing the material wore an apron, gloves, mask, and facial protection during handling.

\section{Sample processing and storage}

The stool preparation procedure for FMT was carried out in an appropriate and exclusive space (biological risk level 2). After weighing, feces were transferred to a container containing $0.9 \%$ non-bacteriostatic saline solution in the proportion of $50 \mathrm{~g}$ of feces for each $250 \mathrm{~mL}$ of saline. The mixture was homogenized manually for two to five minutes. The suspension was transferred carefully to another container previously prepared with a funnel gauze filter, five overlapping open gauzes and elastic for fixation. The suspension was filtered through gauze twice, in order to remove dietary fibers and coarse dirt that could obstruct the colonoscope's working channel. After filtration, glycerol was added for cryoprotection (preventing the formation of crystals) to get final concentration of $10 \%$. The fecal suspensions were then placed in plastic containers with lids and stored in an ultra-freezer at $-80^{\circ} \mathrm{C}$ until use. The viability time established from preparation to administration was six months.

\section{Defrosting and preparing material for infusion}

On the day of the transplant, 250 to $300 \mathrm{~mL}$ of fecal suspension was removed from the ultra-freezer and thawed. The aliquots were thawed at room temperature, at $4^{\circ} \mathrm{C}$ and/or in a water bath at $37^{\circ} \mathrm{C}$. The method chosen for thawing varied according to the time of the procedure. After complete defrosting, the material was transferred to $60 \mathrm{~mL}$ syringes, without a needle, with the aid of a 14 Fr gauge aspiration probe. The syringes were sealed, identified and packed in their own container (stainless steel vat) for transportation in a styrofoam box containing gel ice. Once thawed, fecal suspension should be used within six hours if at room temperature or up to eight hours under refrigeration. The samples could not be frozen again if they were not used.

\section{Receptors inclusion criteria}

Patients with recurrent or refractory CDI infection who agreed 
to participate in the research by completing the informed consent form were included.

\section{- Definition of recurrent and refractory C. difficile infection}

Recurrent infection was defined as the development of a new CDI within eight weeks of a previous episode adequately treated, in which there was an initial resolution of symptoms. Recurrence was characterized by the presence of diarrhea, with more than three daily excrement, with unformed feces (Bristol 6 or 7), during minimum period of time of 48 hours, and positive laboratory results using GDH ECO Test - TR.0032 (Eco Diagnóstica, Minas Gerais, Brazil) confirmed by toxigenic culture ${ }^{(42)}$. Refractory infection was defined as persistent infection, with no improvement in symptoms, despite antimicrobial treatment with oral vancomycin for at least five days.

\section{- Intensity of C. difficile infection}

- Complicated CDI: infection complicated with toxic megacolon, peritonitis, hemodynamic instability, respiratory failure or need for surgical approach.

- Severe CDI: one of the following criteria (bloody diarrhea, pseudomembranous colitis, adynamic ileus, severe abdominal pain, fever with an axillary temperature greater than $38.9^{\circ} \mathrm{C}$, serum albumin below $2.5 \mathrm{~g} / \mathrm{dL}$, higher global leukocyte count at 20.000 cells $/ \mathrm{mm}^{3}$, acute renal failure).

- Mild to moderate CDI: diarrhea without additional criteria that characterize a severe or complicated condition ${ }^{(43)}$.

\section{Receptors exclusion criteria}

- Pregnancy.

- Septic shock defined as: sepsis requiring a vasopressor to raise mean arterial pressure $\geq 65 \mathrm{mmHg}$ and lactate $>2 \mathrm{mmol} / \mathrm{L}$ despite adequate volume expansion.

- Life expectancy less than three months.

- Patients unable to undergo colonoscopy.

- Inability to complete the informed consent form (own patient or related family member).

- Absence of criteria for recurrent or refractory CDI.

- Those who refuse or give up participating in the research.

\section{Management of receptors before the fecal microbiota transplantation}

The transplant candidates underwent a medical interview to characterize the clinical history. The following variables were assessed: pre-existing comorbidities, Charlson score, medications in use, history of allergies, duration of symptoms, number of bowel movements per day, stool shape according to the Bristol scale, and previous treatments for $\mathrm{CDI}^{(44,45)}$. A stool sample was collected for diagnostic confirmation and storage. The diagnosis was confirmed through the GDH test and toxigenic culture. Patients have received $125 \mathrm{mg}$ oral vancomycin, $6 / 6 \mathrm{~h}$, for 10 to 14 days before FMT in order to reduce the intestinal population of $C$. difficile. The vancomycin was interrupted with an interval of 12 to 24 hours before the procedure. Patient and family members were instructed on how to disinfect home bathrooms with a sporicidal agent. It was recommended to use $0.525 \%$ sodium hypochlorite ( $9: 1$ water solution with bleach) for cleaning the bathroom, door handles, toilet bowl, sinks and taps on the day of the procedure. The patient was instructed not to use the bathroom until the FMT was performed.

\section{Bowel preparation and route of administration}

Patients received usual intestinal preparation for colonoscopy with polyethylene glycol (PEG 4000), dimethicone and bisacodyl. Osmotic laxative was taken in two doses: $120 \mathrm{~g}$ of PEG was diluted in one liter of water and administered orally in the night before and in the morning of the procedure. A $15 \mathrm{~mL}$ vial of $75 \mathrm{mg} / \mathrm{mL}$ dimethicone was diluted in the second dose of the preparation. Four bisacodyl $5 \mathrm{mg}$ tablets and a diet without residue were used the day before. The recommended fasting was 8 hours for small meals and 2 hours for clear liquids, without residue. Two hours before FMT, patients received $4 \mathrm{mg}$ of loperamide orally. All colonoscopies were performed by a single researcher in the Endoscopy Department of HC-UFMG with a double working channel device (Fujinon EC-530DM/DL). Patients received analgesics and hypnotics for deep sedation under anesthesiologist assistance. The device was inserted up to the cecum, with little insufflation and maneuvers to undo handles when indicated. When delimiting the cecum, as much air as possible was aspirated and the patient was positioned in the right lateral decubitus position with the objective of retaining, by gravity, the material in the right colon and cecum. After correct positioning, the fecal substrate was infused into the caecum plus $10 \mathrm{~mL}$ of air injected into the working channel to use all the material. The device was removed without air insufflation and without assessment of mucosa, in order to avoid distension and peristaltic stimulation. After the FMT, patients were referred to the postanesthetic recovery room where they remained lying in the right lateral decubitus position for one hour in order to retain the transplanted material as much as possible. Patients were evaluated and released home on the same day. The stages of the donation process, sample preparation and administration are shown in FIGURE 5.

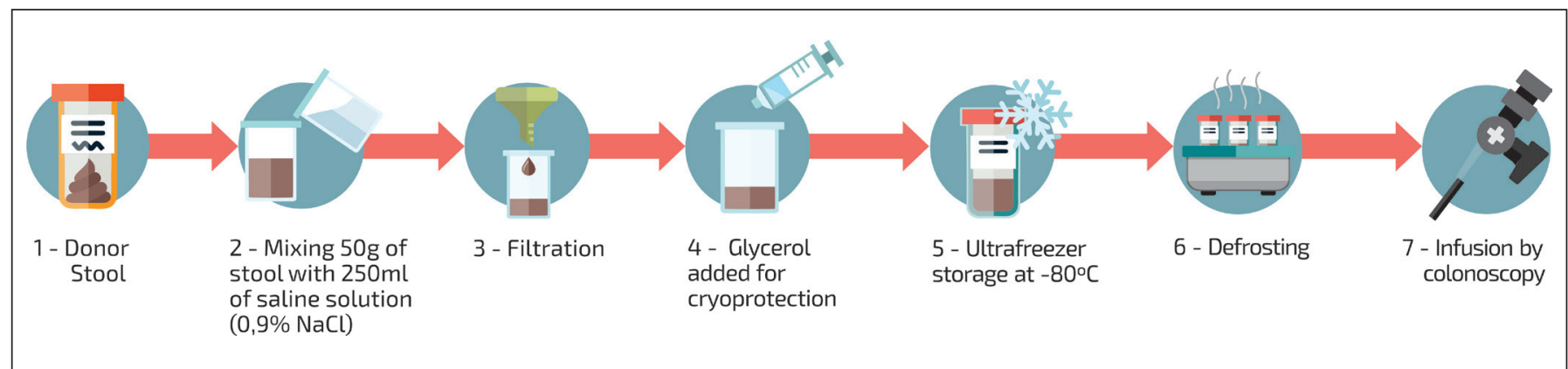

FIGURE 5. Phases of fecal microbiota transplantation with stool bank. 


\section{Post monitoring fecal microbiota transplantation}

After transplant, receivers were monitored regularly to assess the effectiveness and occurrence of possible adverse events in the short and long term. In the first week, patients were assisted daily, by telephone contact, with a symptom approach, investigation of possible endoscopic complications, adverse events and evaluation of diarrhea resolution. If serious side effects were suspected or persistent complaints were registered, patients were personally assessed by the researcher. After the first week, the follow-up was done within eight weeks, three months, six months and, subsequently, annually. The patients sent, after seven and 21 days of transplantation, a sample of feces stored in a common examination bottle, in a sealed styrofoam box, under refrigeration, to be stored in our laboratory. Participants were instructed to contact the researcher on suspicion of recurrence of CDI or in the presence of any complaint or adverse event.

\section{- Definition and classification of adverse events}

Adverse events were defined as any undesired occurrence after FMT, without the need for an exact causal relationship. Symptoms, disease onset or laboratory findings were considered.

They were classified according to severity in:

- minor events - mild symptoms, such as abdominal discomfort, diarrhea, constipation, flatulence, borborygmus, abdominal bloating, nausea, vomiting and fever with spontaneous resolution;

- major events - endoscopic complications (perforation, bleeding), complications related to sedation (bronchoaspiration), transmission of pathogens, exacerbation of inflammatory bowel disease, occurrence of infection (peritonitis, pneumonia), need for hospitalization, temporary or permanent functional disability or death.

Regarding the time of occurrence, they were classified as:

- short term - occurrence within one month after the FMT;

- medium term - between one month and one year;

- long term - after one year.

As for causality, they were classified into:

- definitely related - there was a reasonable temporal sequence, with an expected response pattern and not explained by another hypothesis;

- probably related - there was a reasonable time sequence, with an expected response pattern and unlikely to be explained by the patient's characteristics or other interventions;

- possibly related - despite the temporal relationship, it is possible that it is caused by factors other than transplantation;

- unrelated - event that is certainly unrelated to treatment.

\section{- Definition of therapeutic failure and CDI resolution}

The occurrence of diarrhea in the first eight weeks after transplantation was considered a therapeutic failure, characterized by more than three daily bowel movements, with unformed stools (Bristol 6 or 7) for a period longer than 48 hours and CDI confirmed by GDH test and toxigenic culture. These patients were offered a new FMT with feces from another donor. The resolution of CDI was defined based on clinical criteria, characterized by the absence of diarrhea, leukocytosis and abdominal pain at the end of eight weeks of treatment. The resolution rate can be primary if achieved with just one FMT, or it can be general if new procedures are needed to achieve therapeutic success within an eight-week period.

\section{Statistical analysis}

Statistical analysis of the data was performed using the SPSS program (IBM Corp. Released 2013; IBM SPSS Statistics for Windows, Version 21.0. Armonk, NY: IBM Corp.). The numerical variables were presented as means and standard deviation or as medians and range when the distribution was not Gaussian. Categorical variables were presented in absolute numbers and percentages.

\section{RESULTS}

Over a five-month period (September 2017 to February 2018) a total of 134 candidates were recruited to participate in the donor selection process. After self-assessment, candidates who met at least one of the exclusion criteria were eliminated from the screening process. Of the 134 possible candidates for donation, only $33(24.6 \%)$ qualified as potential donors and went on to the second stage.

This subgroup underwent clinical evaluation that includes medical interview and detailed physical examination. The characteristics of potential donors are shown in TABLE 1 . It was compound by 20 women and 13 men, with an average age of $32.9 \pm 9.2$ years, average body weight of $69 \pm 12.8 \mathrm{~kg}$, height of $1.7 \pm 0.10$ meters and BMI of $23.8 \pm 3.40 \mathrm{~kg} / \mathrm{m}^{2}$. Twenty-six $(78.8 \%)$ candidates were not related to possible receivers.

TABLE 1. Characteristics of the 33 potential donors.

\begin{tabular}{lc}
\hline Variable & $\mathbf{N}(\%) /$ mean \pm SD \\
\hline Gender & $13(39.4 \%)$ \\
$\quad$ Male & $20(60.6 \%)$ \\
Female & $32.9(18-50)$ \\
Age (years) & $69(43.7-92.5)$ \\
Weight $(\mathrm{kg})$ & $1.7(1.5-1.9)$ \\
Height $(\mathrm{m})$ & $23.7(17.5-32.3)$ \\
Body mass index $-\left(\mathrm{Kg} / \mathrm{m}^{2}\right)$ & \\
Relationship with receiver & $7(21.2 \%)$ \\
$\quad$ Relatives & $26(78.8 \%)$ \\
$\quad$ Not related) & \\
Pattern of alcohol consumption & $18(54.5 \%)$ \\
Abstinence & $15(45.5 \%)$ \\
Low consumption (up to 2 doses/day) & None \\
Smoking & $10(30.3 \%)$ \\
Regular use of medicines & $25(75.7 \%)$ \\
Normal intestinal habit & \\
Bristol scale & $2(6.0 \%)$ \\
Type 1 & $6(18.2 \%)$ \\
Type 2 & $19(57.6 \%)$ \\
Type 3 & $6(18.2 \%)$ \\
Type 4 & \\
\hline
\end{tabular}

More than half were married (54.5\%), with a stable relationship. No donor candidate reported problems with alcoholism and $15(45.5 \%)$ reported social consumption, with a maximum daily intake of $20 \mathrm{~g}$ of ethanol for men and $14 \mathrm{~g}$ for women. None were smokers and $69.7 \%$ did not use medications continuously. The majority $(75.8 \%)$ had a regular bowel habit, with normal stools, classified as type 3 and 4 by the Bristol scale. 
Based on feature described, $24(72.7 \%)$ candidates were excluded for presenting any clinical contraindication. The main contraindications found in the second stage were: occurrence of acute diarrhea in the last six months, overweight (BMI $\geq 25 \mathrm{~kg} / \mathrm{m}^{2}$ ) and gastrointestinal disorders (constipation, irritable bowel syndrome, dyspeptic complaints and food intolerances). Half of the participants presented more than one contraindication. One candidate in particular was excluded for five reasons: acute diarrhea in the last six months, use of antibiotics in the last three months, tattooing in the last six months, risky sexual behavior and use of illicit drugs.

Nine participants continued the process and underwent blood and stool tests. Five $(55.6 \%)$ were excluded based on the following reasons: presence of occult blood in the feces, presence of free-living protozoa (Endolimax nana and Entamoeba coli), positive test for Salmonella sp. and Isospora belli. Of a total of 33 potential donors, only four $(12.1 \%)$ were selected after complete screening. The overall donor detection rate, considering all recruited candidates, was $3 \%$. The exclusion criteria and results of donor selection are shown in TABLE 2 and FIGURE 6.

The candidate excluded due to the presence of occult blood in the feces was a female volunteer, 40 years old, married, nulligest and unrelated to the receptor. After extensive investigation a deep endometriosis of the cecum was found and surgically removed. Of the four qualified donors, three were relatives of a possible receptor

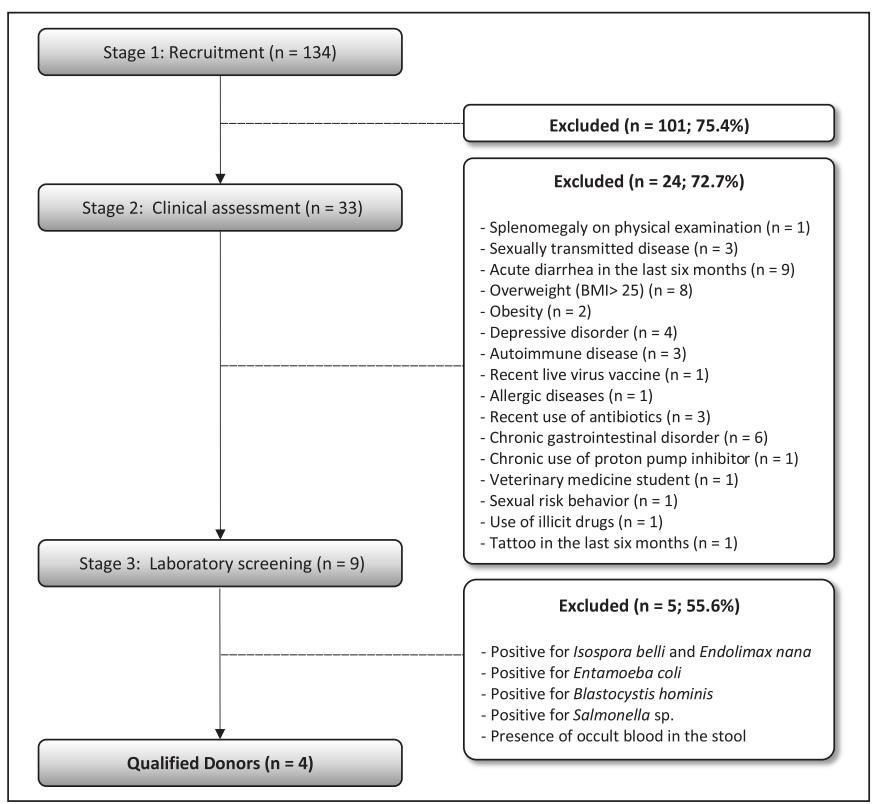

FIGURE 6. Three-step approach to donor selection process and main contraindications detected.

TABLE 2. Exclusion criteria for 29 potential donors.

\begin{tabular}{|c|c|c|c|}
\hline Candidate & Gender & Age (years) & Exclusion criteria \\
\hline 1. NCRG & $\mathrm{F}$ & 27 & Student of veterinary medicine \\
\hline 3. LFFR & M & 21 & Overweight \\
\hline 5. LGFR & M & 21 & Overweight \\
\hline 6. ECF & $\mathrm{F}$ & 41 & Overweight \\
\hline 7. JJGB & $\mathrm{M}$ & 35 & Genital herpes \\
\hline 9. EOSS & $\mathrm{F}$ & 42 & Overweight, depressive disorder \\
\hline 10. ECAM & $\mathrm{F}$ & 38 & Acute diarrhea in the last six months \\
\hline 11. GMM & $\mathrm{F}$ & 39 & Acute diarrhea in the last six months \\
\hline 12. RMM & M & 31 & Overweight \\
\hline 13. NCR & $\mathrm{F}$ & 41 & Genital herpes, overweight, depressive disorder \\
\hline 14. AVAS & $\mathrm{F}$ & 21 & Angioedema, recent vaccine with live attenuated virus \\
\hline 18. WSLR & $\mathrm{F}$ & 50 & Chronic constipation, obesity, functional dyspepsia, chronic use of proton pump inhibitor \\
\hline 19. DMA & M & 28 & Vitiligo \\
\hline 20. DL & M & 28 & Genital warts \\
\hline 21. LR & M & 38 & Acute diarrhea in the last six months \\
\hline 22. PNA & $\mathrm{F}$ & 22 & Acute diarrhea in the past six months, chronic constipation, depressive disorder, recent antibiotic use \\
\hline 23. IC & $\mathrm{F}$ & 18 & Splenomegaly on physical examination \\
\hline 24. MAP & M & 25 & $\begin{array}{l}\text { Risky sexual behavior, use of illicit drugs, tattooing in the last six months, acute diarrhea in the last six } \\
\text { months, recent use of antibiotics }\end{array}$ \\
\hline 25. HRVC & M & 34 & Positive for Isospora belli and Endolimax nana \\
\hline 26. CNMCG & $\mathrm{F}$ & 35 & Positive for Entamoeba coli \\
\hline 27. MAV & $\mathrm{F}$ & 48 & Positive for Blastocystis hominis \\
\hline
\end{tabular}

F: female; M: male. 
who was being assessed for eligibility for FMT. However, the patient responded favorably to treatment with oral vancomycin for eight weeks and was not submitted to FMT. The three related donors performed only one stool collection each and lost follow-up after discarding the need for fecal transplant.

The remaining donor performed three collections in the period between March and December 2018. She evolved with recurrent abdominal pain and was referred for evaluation at the Gastroenterology outpatient clinic of HC-UFMG. However, after an initial evaluation, she showed clinical improvement and lost follow-up, making no further donations.

After that period, 21 new candidates with an appropriate clinical profile were recruited. One of them, during the protocol examinations, had presence of Entamoeba coli cysts detected in a stool sample. We then opted for treatment with secnidazole $2 \mathrm{~g}$, orally, single dose and new stool collection, in three serial samples, after 15 days of treatment. The same was offered to the candidate who had been excluded in the first selection process. Control tests from both donors were negative for free-living protozoa and candidates were accepted as donors.

Donations and stool preparation took place according to the standard operating procedure developed and approved by the transplantation center. No changes were identified that prevented the collection of feces on the day of collection. In total, 16 donations were made between October 2017 and March 2020. Donors collected the material in the morning in a clean, dry plastic container. The material was packed in a styrofoam box, sealed, identified with name, date, collection time and sent to the FMTC laboratory. The first donation arrived after $1 \mathrm{~h} 40 \mathrm{~min}$ of the collection. It remained refrigerated between $2^{\circ} \mathrm{C}$ and $8^{\circ} \mathrm{C}$ and was processed the next day, with a total time between collection and storage of $29 \mathrm{~h}$. All other donations had a median time between collection and storage of 4h30min (TABLE 3). The median fecal weight donated was $71.3 \mathrm{~g}$ and the volume generated was $362.2 \mathrm{~mL}$. Eleven transplants were performed using $280 \mathrm{~mL}(250-300 \mathrm{~mL})$ of fecal substrate in each procedure. The time between the beginning of defrost and infusion of the fecal substrate was less than six hours.

TABLE 3. Characteristics of stool donations and sample preparation.

\begin{tabular}{lc}
\hline Variable & N / mean \pm SD \\
\hline Total number of donations & 16 \\
Donor 1 & 1 \\
Donor 2 & 1 \\
Donor 3 & 1 \\
Donor 4 & 3 \\
Donor 5 & 4 \\
$\quad$ Donor 6 & $3 \pm 1$ \\
Number of bottles per collection & $71.3 \pm 29.1$ \\
Weight of samples collected (g) & $362.2 \pm 168.7$ \\
Volume generated at each donation (mL) & $4 \mathrm{~h} 30 \mathrm{~min} \pm 73 \mathrm{~min}$ \\
Time to storage & $2 \mathrm{~h} 50 \mathrm{~min} \pm 63 \mathrm{~min}$ \\
Defrost time & $1 \mathrm{~h} 18 \mathrm{~min} \pm 48 \mathrm{~min}$ \\
Time between defrost and beginning of infusion \\
Volume prepared for infusion (mL) & $280 \pm 22.9$ \\
\hline
\end{tabular}

\section{DISCUSSION}

\section{Donor screening}

For the full functioning of a FMTC, it is necessary to recruit a large number of potential donors and select, among them, only healthy ones. Finding donors is a major challenge for structuring a transplant center, given the rigor of the selection process and the lack of evidence-based guidelines. Current criteria for donor screening and selection come mainly from regulatory institutions guidelines or scientific societies, based on expert opinion. There are no randomized clinical trials on donor characteristics and transplant effectiveness. In addition, the concept of healthy microbiota is still under construction. Previous studies used as a parameter of healthy microbiota that from healthy donors, with normal weight for height and without chronic diseases, allergies, high-risk behavior for sexually transmitted infections, family history of malignancy or chronic medication use $\mathrm{s}^{(9,12,46)}$.

Donor selection recommendations require candidates to undergo screening similar to that used for blood donations. The questionnaire must be able to identify risk factors or diseases with risk of transmission through the FMT. Some protocols also require monitoring at the time of donation to track changes in the interval between application of the questionnaire and donation of feces ${ }^{(9,39)}$.

As general guidelines, only healthy adults, without chronic or acute illnesses, are qualified as stool donors. The selection is based on the identification and exclusion of candidates who present unfavorable conditions such as: (1) infectious diseases transmitted by blood and possibly by FMT, (2) conditions for which there is a reasonable possibility of transmission, (3) morbidities in which the microbiota plays a role in pathogenesis, (4) situations that increase the likelihood of transmitting infections from multidrug-resistant organisms (MDRO).

Almost all studies on FMT emphasize caution with screening donors given the risk of transferring infectious pathogens and the potential risk of transmitting phenotypes associated with dysbiosis, such as atherosclerosis, colorectal neoplasia, obesity, among others ${ }^{(47-51)}$. The caution is similar to that used in blood centers, especially after the HIV epidemic in the 1980s and cases of transmission of Hepatitis C by blood transfusion, before its discovery in 1989. The precautionary principle aims to ensure that the risk of transmitting infectious diseases is reduced to very low levels.

Stool donation should be voluntary. Donors should be informed about all stages of the screening process, about conducting a medical interview, physical examination, blood and stool tests and the measures guaranteed to keep the process confidential. They must be informed of the potential risks and benefits of the donation and agree to the informed consent form. Candidates must be at least 18 years old and commit to providing honest answers, informing the transplant center if they become ill. They must allow their data and fecal samples to be stored and tested in the future if serious adverse events occur. It is also ensured that the donor can withdraw from the process at any time without any harm. All informed consent form must be stored for at least 10 years.

Despite seeming innocuous, the selection process presents considerable risks as exemplified in the present study. The discovery of an indolent disease, in an asymptomatic phase, should be considered before the investigation begins. The risk and emotional effect with false positive results should also be discussed with the candidate. On the other hand, the selection process can generate 
some benefits for the donor, such as the opportunity for a broad and non-invasive assessment of their health status and the possibility of the exercise of altruistic gesture, inherent to donations.

\section{- Clinical criteria for donor selection}

Meta-analysis of 168 clinical studies on FMT, of which 108 were on CDI, shows that the exclusion criteria are heterogeneous in more than $50 \%$ of the studies ${ }^{(52)}$. The main clinical criteria for donor exclusion were recent use of antibiotics followed by gastrointestinal disorders and a history of malignancy. Gastrointestinal disorders include irritable bowel syndrome, inflammatory bowel disease, constipation and chronic diarrhea. Other common criteria were high-risk sexual behavior, tattoos and piercings. Less than half of the studies excluded diseases such as metabolic syndrome, psychiatric, neurological disease or diabetes mellitus.

Most candidates are excluded from the process after careful medical evaluation. Data from OpenBiome, a large American stool bank, shows that $67.8 \%$ of applicants who remained in the program after a medical interview were excluded due to clinical criteria, with emphasis on the presence of asthma, atopy, medication use, psy- chiatric conditions and a history of infectious diseases ${ }^{(22)}$. A similar data was found in an Australian bank, excluding approximately $50 \%$ of donors after a clinical questionnaire ${ }^{(53)}$. In the present study, clinical criteria were able to exclude $72.7 \%$ of potential donors and reduce expenses with blood and stool tests in a more restricted group. Developing screening tools like ours is extremely important in emerging countries, where the good management of financial resources has a great impact on population health.

Comparison between the first transplant protocols and the latest International Consensus on FMT shows that the clinical criteria used in our institution are more rigorous than those used in first studies and similar to those currently recommended. This protocol stands out for having selected donors who are not overweight, with a narrower age range and a longer microbiota recovery interval after an episode of acute diarrhea (six months versus two months). In addition, it adds criteria not used in the first studies, such as a history of psychiatric disorders, chronic use of proton pump inhibitors, diabetes mellitus, neurological disorders, chronic painful syndrome and recent use of live attenuated virus vaccine (TABLE 4).

TABLE 4. Clinical exclusion criteria for stool donation.

\begin{tabular}{|c|c|c|c|c|}
\hline Exclusion criteria & $\begin{array}{c}\text { FMT workgroup } \\
\text { recommendations (2011) }\end{array}$ & $\begin{array}{c}\text { Amsterdam Protocol } \\
(2013)\end{array}$ & $\begin{array}{l}\text { International Consensus } \\
\text { on Stool Banking (2019) }\end{array}$ & $\begin{array}{l}\text { Protocol IAG } \\
\text { HC-UFMG }\end{array}$ \\
\hline $\begin{array}{l}\text { Risk factor or history of } \\
\text { transmissible disease }\end{array}$ & $\checkmark$ & $\checkmark$ & $\checkmark$ & $\checkmark$ \\
\hline ATB use in the last 3 months & Excluded if $<3$ months & $\checkmark$ & $\checkmark$ & $\checkmark$ \\
\hline Acute diarrhea & $\checkmark$ & $\checkmark$ & $<2$ months & $<6$ months \\
\hline $\begin{array}{l}\text { Family history of } \mathrm{CaCR} \text { or } \\
\text { polyposis }\end{array}$ & - & $\checkmark$ & $\checkmark$ & $\checkmark$ \\
\hline $\begin{array}{l}\text { Travel to tropical regions in } \\
\text { the last } 3 \text { months }\end{array}$ & Excluded if $<6$ months & $\checkmark$ & $\checkmark$ & Not recommended \\
\hline Health care worker & - & $\checkmark$ & - & $\checkmark$ \\
\hline Diabetes mellitus & - & - & $\checkmark$ & $\checkmark$ \\
\hline History of malignancy or QT & $\checkmark$ & - & $\checkmark$ & $\checkmark$ \\
\hline $\begin{array}{l}\text { Immune disorders or use of } \\
\text { immunosuppressants }\end{array}$ & $\begin{array}{c}\text { Autoimmune disease } \\
\text { was considered a relative } \\
\text { criterion }\end{array}$ & - & $\checkmark$ & $\checkmark$ \\
\hline $\begin{array}{l}\text { History of neurological } \\
\text { disorders or chronic painful } \\
\text { syndrome }\end{array}$ & Relative criterion & - & $\checkmark$ & $\checkmark$ \\
\hline $\begin{array}{l}\text { Chronic use of PPI ( } \geq 3 \\
\text { months) }\end{array}$ & - & - & $\checkmark$ & $\checkmark$ \\
\hline $\begin{array}{l}\text { Angioedema, recent vaccine } \\
\text { with live attenuated virus }\end{array}$ & - & - & $\checkmark$ & $\checkmark$ \\
\hline
\end{tabular}

—, not mentioned; $\checkmark$ recommended; FMT: fecal microbiota transplantation; IAG: Instituto Alfa de Gastroenterologia; HC-UFMG: Hospital das Clínicas, Federal University of Minas Gerais; BMI: body mass index; ATB: antibiotics; QT: chemotherapy, PPI: proton pump inhibitor; $\mathrm{CaCR}$, colorectal cancer. 
There is no consensus on the ideal age of donors. In order to apply the informed consent form, the applicant must be at least 18 years old in Brazil. In addition, the intestinal microbiota of children has less diversity in the first years of life and develops progressively over the years ${ }^{(54)}$. This finding explains, in part, the scarcity of children as donors in the large studies on FMT. Donor ages range from 18 to 50,60 and 65 years old ${ }^{(9,39-41)}$. Increasing age has been associated with changes in the intestinal microbiota, which justifies a preference for donations from people under 50 years or those under 60 and adequately screened for colorectal cancer $^{(22)}$. At this point, some studies recommend testing for fecal occult blood. However, only a minority of them (3.1\%) screened their donors ${ }^{(52)}$. Male and female donors are equally eligible, even with a higher prevalence of autoimmune diseases and functional disorders in women ${ }^{(52)}$. On the other hand, male donors are more likely to provide greater fecal mass ${ }^{(52)}$.

Many non-infectious disorders have been linked to dysbiosis such as neurodegenerative diseases, psychiatric disorders, autoimmune diseases, metabolic syndromes, hepatobiliary and chronic intestinal disorders ${ }^{(55)}$. However, the causal relationship is not as clear as in CDI. Most specialists agree to exclude from the selection process individuals who have disorders related to dysbiosis due to the theoretical risk of long-term transmission ${ }^{(15,21,22)}$. The lack of evidence from long-term follow-up justifies this cautious attitude.

Some studies report a body mass index (BMI) greater than 30 $\mathrm{kg} / \mathrm{m}^{2}$ as exclusion criteria. Experiments in animal models show that microbiota receptors from obese mice increased their adiposity after transplantation even with maintenance of a standardized $\operatorname{diet}^{(56)}$. In addition, among the studies that did not report the donor's BMI, three receptors showed weight gain after FMT, with no other apparent cause ${ }^{(57)}$. Thus, it was decided to be more rigorous excluding candidates with a BMI above $25 \mathrm{~kg} / \mathrm{m}^{2}$ in the present study. Furthermore, there was an additional gain in eliminating candidates with possible disorders associated with overweight such as insulin resistance and metabolic syndrome.

Personal history of cancer should also be investigated in donors and recognized as a contraindication. However, candidates with a history of non-malignant skin cancer who have undergone appropriate treatment may be eligible ${ }^{(22)}$.

Many stool banks exclude health professionals from the screening process due to the occupational risk of biological accidents and the possibility of colonization by MDRO. A systematic review assessed the risk of occupational colonization by MDRO in employees of hospitals and geriatric centers. Despite the methodological limitations and heterogeneity of the studies, the prevalence of colonized professionals was $2.6 \%-48.5 \%$ for pathogens producing expanded spectrum beta-lactamase, $0-9.6 \%$ for vancomycin-resistant enterococci and $0.9 \%-14.5 \%$ for methicillin-resistant Staphylococcus aureus. The real impact of transmission and consequent infection related to health care has not been measured ${ }^{(58)}$. In Brazil, a study with 294 oncology hospital workers identified colonization in the oral cavity by Enterobacteriaceae in only $18.7 \%$, less than half of which was due to multidrug-resistant germs. The study did not identify colonization by extended-spectrum $\beta$-lactamase (ESBL) or Klebsiella pneumoniae producer of carbapenemase ${ }^{(59)}$.

MDRO have become a public health challenge and should be researched in fecal donation candidates ${ }^{(60)}$. The risk of acquiring MDRO is particularly high after traveling to India, Asia and North Africa $^{(61)}$. However, also in Europe, the prevalence of multidrugresistant intestinal bacteria can reach more than $50 \%{ }^{(60)}$.
The FDA issued a recent warning about screening for MDRO in fecal donors after the death by Escherichia coli ESBL invasive infection in a FMT receptor ${ }^{(62)}$. Previously, MDRO research was not recommended by the FDA, although some study centers have already made this assessment. After the publication of two serious invasive infections due to ESBL, one complicated by death, the FDA went on to recommend that screening donors should include questions about risk factors for colonization. Individuals at high risk of colonization should be excluded during clinical evaluation. Examples of high risk are: health professionals, people with a history of recent hospitalization or a stay in long-term health institutions, people who regularly attend medical clinics, or outpatient surgery centers ${ }^{(62)}$.

Travel to tropical countries in the last three months is cited as an exclusion criterion in several studies ${ }^{(9,39,63)}$. The concern is justified by the occurrence of traveler's diarrhea and the possibility of becoming asymptomatic carrier of pathogens. Paramsothy et al. considered the following areas as high risk for traveler's diarrhea: Africa (except South Africa), Middle East, Asia (except Japan and Thailand), Pacific (except Australia and New Zealand), Central America and South America (except Argentina and Chile) ${ }^{(39)}$. Candidate who visited Brazil was automatically excluded from the screening process.

Currently, the destinations considered high risk for traveler's diarrhea are South and Southeast Asia, South and Central America, most African countries, Eastern Europe and some Caribbean islands ${ }^{(64)}$. The main etiologic agents involved in traveller's diarrhea are E. coli enterotoxigenic, Campylobacter, Salmonella, Shigella and norovirus ${ }^{(65)}$. Latin American travelers may also experience norovirus diarrhea, Giardia, Cryptosporidium and Entamoeba ${ }^{(65)}$. Therefore, in order to structure a transplant center in countries such as Brazil, it is necessary to include targeted research for such pathogens during donor screening. Although travel to tropical countries is considered an exclusion criterion by international protocols, the present study shows that it is possible to structure a safe screening program, even in emerging countries like Brazil.

Gastrointestinal infections caused by viruses, bacteria and parasites must also be excluded, especially in asymptomatic carriers. In addition, these infections can promote transient changes in the intestinal microbiota even after eliminating the pathogen, which motivates the contraindication of donations for up to six months ${ }^{(66)}$. Several studies use as an exclusion criterion patients with risky sexual behavior, sexually transmitted diseases, use of illicit drugs, and history of incarceration ${ }^{(15)}$. The use of antibiotics in the last three months also makes the donation unfeasible. Antibiotics promote significant changes in the microbiota and normalization uses to occur three months after the end of treatment ${ }^{(67)}$.

The chronic use of a proton pump inhibitor (PPI) is considered an exclusion criterion for stool donation. Several studies describe an association between chronic use of PPI and $\mathrm{CDI}^{(68)}$. In addition, it is known that PPI are associated with an increased risk of small intestinal bacterial overgrowth, a condition that can impact the donor's intestinal microbiota ${ }^{(69)}$. However, a minority of studies exclude chronic users of $\mathrm{PPI}^{(52)}$.

\section{- Laboratory criteria for donor selection}

All candidates who pass the medical interview must undergo blood and stool tests to assess possible conditions that may confer an increased risk of transmitting infections. The main purpose of laboratory tests is to identify asymptomatic carriers and/or detect 
prohibitive subclinical changes. Large studies on donor selection have shown that a high number of candidates are excluded because they are asymptomatic carriers of pathogens ${ }^{(9,39,63)}$. However, there is significant heterogeneity in the screening tests between the various studies on FMT. A systematic review selected 168 articles on screening of 1513 donors and found that it was incomplete in more than $50 \%$ of published studies ${ }^{(52)}$.

The main pathogens investigated in clinical trials are: human immunodeficiency virus (HIV), hepatitis A, B and C virus, syphilis, C. difficile, Salmonella sp., Shigella sp., Campylobacter sp., Cryptosporidium sp. and enteric parasites. Less than half of studies researched Giardia, Yersinia, E. coli $\mathrm{O} 157$ and H. pylori and less than a third cytomegalovirus, human $\mathrm{T}$ lymphotropic virus and Epstein-Barr virus ${ }^{(52)}$. It is unanimous that donors need to be tested for human immunodeficiency virus (HIV), hepatitis $\mathrm{B}$ and hepatitis $\mathrm{C}$ virus. It is also recommended to search for the Human T-Lymphotropic Virus (HTLV), multiplex PCR to detect rotavirus, norovirus and adenovirus according to local epidemiological specificities ${ }^{(47)}$.

Common reasons for donor exclusion based on fecal examinations in developed countries were the detection of Dientamoeba fragilis, Blastocystis hominis, $C$. difficile and rotavirus. Exclusion by serological tests was less frequent. There are reports of exclusion due to apparent exposure to Strongyloides and indeterminate serum levels of antibodies against hepatitis $\mathrm{C}$ virus ${ }^{(9,39,63)}$.

The search for Epstein-Barr virus (EBV) and cytomegalovirus (CMV) can be considered. There is no agreement on the selection or exclusion of these donors. The European Consensus on FMT recommends that individuals with positive EBV and CMV serology should be excluded ${ }^{(47)}$. On the other hand, the International Consensus on stool bank recommends that donors positive for CMV or EBV should not be excluded. As an option, only cases of active or recent infection (positive $\operatorname{IgM}$ ) should be excluded ${ }^{(22)}$. The reason is that there is a high prevalence of previous exposure to both viruses and there are no reported cases of diseases associated with CMV or EBV attributable to fecal transplantation, even among immunosuppressed individuals. It is estimated that the seroprevalence of the Epstein-Barr virus in the world population is $90 \%-95 \%{ }^{(70)}$. The same trend is observed in relation to CMV, with seroprevalence ranging from 80 to $100 \%$ in emerging countries ${ }^{(71)}$.

In Brazil, few studies on the prevalence of infection by EBV and CMV have been published. A study carried out in São Paulo state, with healthy blood donors, demonstrated positive EBV IgG antibody in $94.44 \%$ of the samples ${ }^{(70)}$. A nationwide study that evaluated 1045 Brazilian blood donor samples found a prevalence of CVM IgG antibody in $96.45 \%$ of the candidates ${ }^{(72)}$. In Minas Gerais state, IgG positivity for CMV in pregnant and postpartum women is greater than $85^{\circ}{ }^{(73)}$. In this scenario, the validity of EBV and CMV serology in healthy donors already submitted to a rigorous clinical questionnaire is debatable.

The presence of nematodes and protozoa infection should be assessed based on the clinical, social and geographical characteristics of each region. Special attention to Strongyloides stercoralis due to the risk of disseminated infection, especially in immunosuppressed individuals. The isolated presence of symptoms should not be used for parasitic diseases such as strongyloidiasis, since most patients with chronic infection are asymptomatic. Based on parasitological examinations, the occurrence of strongyloidiasis in southeastern Brazil is $3.9 \%{ }^{(74)}$. The most common method for diagnosis is direct microscopy of the parasite in the stool. However, during chronic infection, the detection of the pathogen may be intermittent, with sensitivity in a single sample of up to $66^{(75)}$. To increase the sensitivity, it is recommended to repeat samples collection or concentration techniques such as Baermann-Morais method ${ }^{(76)}$. Serological tests can also be used, with sensitivity around $70 \%-97 \%$ and specificity of $87 \%-100 \%{ }^{(77)}$. However, patients may experience false-positive reactions with other nematodes, especially in regions of higher prevalence, reducing the positive predictive value of the test. In addition, individuals may also have persistent positive antibodies after successful therapy, limiting the value of this test in the diagnosis of active infection.

Brazil is an endemic country for Schistossoma mansoni infection particularly found in states in the northeast region and some regions of Minas Gerais state. The gold standard for diagnosis is the oogram - fresh examination of material resulting from the collection of six to nine fragments of the Houston valves. However, the test requires an invasive procedure impracticable in healthy donation candidates. Serological tests are mainly directed against antigens of $S$. mansoni. They are highly sensitive, but moderately specific, and therefore a good tool for screening patients in endemic areas. Antibodies remain detectable for long periods after treatment and, consequently, serology does not differentiate between active and previous infection.

Giardia duodenalis is a protozoan with worldwide distribution, found especially in areas of poor sanitary condition ${ }^{(78)}$. It causes epidemic or sporadic diarrhea, with emphasis on groups considered to be at high risk such as infants, travelers and immunosuppressed. The most widely used diagnostic method is direct microscopic examination of stool. Microscopy is specific for the detection of trophozoites and Giardia cysts. Nevertheless, it has certain limitations such as reduced sensitivity in a single stool sample. To increase the sensitivity, it is necessary to perform a serial collection of three samples since the cysts are eliminated intermittently. For healthy donors without gastrointestinal symptoms, the test is aimed at researching cysts, with the trophozoites being the forms most commonly found in liquid stools. On the other hand, methods for detecting antigens in feces show better diagnostic performance, with sensitivity of up to $82 \%$ and specificity of $91.5 \%$ in some studies ${ }^{(78)}$.

Brazil is also considered a country with a high prevalence of amoebiasis $^{(79)}$. Approximately $90 \%$ of infected individuals are asymptomatic carriers, which makes screening this pathogen essential in asymptomatic donors. The diagnosis of amoebiasis can be made with microscopy, serology or fecal antigens. Serological tests have a sensitivity of $90 \%$ to $93 \%{ }^{(79)}$, but are of little use for diagnosis in endemic areas since they are not able to distinguish acute infection from previous contact. A negative result in an asymptomatic donor is useful in excluding the disease and a good tool for screening. Microscopy is able to identify cysts or trophozoites in the stool. However, it is necessary to collect three samples on alternate days to achieve a detection rate of $85 \%-95 \%$. As a disadvantage, microscopic examination is not able to differentiate Entamoena histolytica (pathogenic form), from E. dispar or E. moshkovskii (non-pathogenic forms) ${ }^{(79)}$. The detection of fecal antigens is more sensitive than microscopy and is useful in this differentiation.

The search for $C$. difficile must be performed in all donors. However, the best screening method in an asymptomatic population has not been standardized. The main studies used molecular tests for toxigenic strain (PCR) associated or not with a second method such as immunoenzymatic assay, glutamate dehydrogenase or toxigenic culture $^{(9,39,63,80)}$. The gold standard method for the detection of 
C. difficile is the toxigenic culture. However, the test is not widely available, it requires more time to release the result and complex logistics for its execution. Many laboratories have commercial assays for combined antigen/toxin detection and/or molecular assays for detecting the tcdA or tcdB gene. These are standardized tests for symptomatic patients with unformed stools. Previously, a commercial nucleic acid test demonstrated a higher negative predictive value for symptomatic patients than glutamate dehydrogenase or a multistage test algorithm ${ }^{(81)}$. Nonetheless, a recent detection study of $C$. difficile in asymptomatic patients shows that GDH has a negative predictive value of $99.3 \%$, very similar to the commercial nucleic acid amplification test (NAAT) $-99.9 \%{ }^{(82)}$. Such findings suggest that the use of GDH or NAAT, complemented or not with toxigenic culture, is appropriate for screening asymptomatic donors, as is done in the FMTC of the IAG-HC/UFMG.

Some researchers recommend biochemical and hematological analysis such as complete blood count, C-reactive protein, renal function, hepatic and metabolic biochemistry to exclude relevant undiagnosed diseases. C-reactive protein, despite being a nonspecific inflammatory marker, is useful in identifying an underlying inflammatory state not assessed during clinical evaluation.

Other tests may be recommended. Fecal calprotectin has been used in some studies because it is a good screening test in patients with diarrhea ${ }^{(47)}$. However, its use in healthy and asymptomatic adults remains unknown, which justifies not using this method in the present study. Chronic infection with Helicobacter pylori should be investigated if the route of administration of the transplant through the upper gastrointestinal tract as a nasogastric catheter or by lyophilized capsules. Such research is not necessary if the FMT is by colonoscopy ${ }^{(47)}$. There is insufficient data to indicate screening for fungi in possible donors.

Little is known about the ideal donor screening criteria. Consequently, all possible candidates are subjected to extensive screening methods. Studies describe that the rigor in the selection is high, with eligibility rates that can reach $3 \%$, which makes the recruitment of donors a limiting factor for $\mathrm{FMT}^{(22,83,84)}$. In other studies, only 10 and $32 \%$ of possible candidates met all the criteria for donation ${ }^{(39,63)}$. In the present study, criteria similar to those recommended by the main protocols were used (TABLES 5 and 6), with donor detection rate similar to that described in the literature. The overall detection rate was $3 \%$ while the detection among potential donors was $12.1 \%$.

\section{Screening frequency in donors}

There is no consensus on the timing and frequency of examinations at loyal donors. Stool can be donated daily and repeating the complete blood and stool screening with each donation is unreasonable. The recommended frequency of exams varies from once every four weeks, every four months, and up to every six months $s^{(9,21,39,40)}$. Rode et al. recommend that donated feces remain in quarantine for 30 days until further clinical and laboratory screening (blood and stool tests) is carried out and the material is then released for clinical use ${ }^{(85)}$. In OpenBiome, feces are collected for 60 days after the first screening and remain in quarantine until the second (60 days). A third screening is performed later for conditions with a

TABLE 5. Blood tests recommended for screening fecal donors.

\begin{tabular}{|c|c|c|c|c|}
\hline Exams & $\begin{array}{c}\text { FMT workgroup } \\
\text { recommendations }(2011)\end{array}$ & $\begin{array}{c}\text { Amsterdam Protocol } \\
(2013)\end{array}$ & $\begin{array}{l}\text { International Consensus } \\
\text { on Stool Banking (2019) }\end{array}$ & $\begin{array}{c}\text { Protocol IAG } \\
\text { HC-UFMG }\end{array}$ \\
\hline HIV 1 and 2 & ( & $\begin{array}{l}\text { Combined antigen/ } \\
\text { antibody assay }\end{array}$ & $\checkmark *$ & $\begin{array}{l}\text { HIV antibodies and p24 } \\
\text { antigen }\end{array}$ \\
\hline Hepatitis A virus & $\operatorname{IgM}$ & $\begin{array}{c}\text { Total antibodies if IgM } \\
\text { positive }\end{array}$ & $\sqrt{ } *$ & IgG and IgM \\
\hline Hepatitis B virus & $\begin{array}{l}\text { HBsAg, anti-HBc (IgG and } \\
\text { IgM), and anti-HBs }\end{array}$ & $\mathrm{HBsAg}$ and anti-HBs & $\checkmark *$ & $\begin{array}{l}\mathrm{HBsAg} \text {, anti-HBc (IgG and } \\
\text { IgM), and anti-HBs }\end{array}$ \\
\hline Hepatitis $C$ virus & Anti-HCV & Anti-HCV & $\sqrt{ } *$ & Anti-HCV (total antibodies) \\
\hline Hepatitis E virus & - & - & $\sqrt{ } *$ & - \\
\hline HTLV 1 and 2 & - & Antibodies & - & Antibodies \\
\hline Cytomegalovirus & - & IgG and IgM & \pm & - \\
\hline Epstein-Barr virus & - & IgG and IgM & \pm & - \\
\hline Treponema pallidum & RPR and FTA-ABS & Haemagglutination test & $\checkmark *$ & VDRL \\
\hline Trypanosoma cruzi & - & - & - & $\begin{array}{c}\text { Antibodies } \\
\text { (hemagglutination } \\
\text { and indirect } \\
\text { immunofluorescence) }\end{array}$ \\
\hline Strongyloides stercoralis & - & ELISA & $\sqrt{ } *$ & - \\
\hline Entamoeba histolytica & - & $\begin{array}{c}\text { Agglutination and dipstick } \\
\text { test }\end{array}$ & - & - \\
\hline Schistossoma mansoni & - & - & - & $\operatorname{IgG}$ \\
\hline Blood cell count & - & - & $\checkmark$ & $\checkmark$ \\
\hline Metabolic panel & - & - & $\checkmark$ & $\checkmark$ \\
\hline Hepatic panel & - & - & $\checkmark$ & $\checkmark$ \\
\hline C-reactive protein & - & $\checkmark$ & $\checkmark$ & $\checkmark$ \\
\hline
\end{tabular}


TABLE 6. Stool tests recommended for screening fecal donors.

\begin{tabular}{|c|c|c|c|c|}
\hline Exams & $\begin{array}{l}\text { FMT workgroup } \\
\text { recommendations } \\
(2011)\end{array}$ & $\begin{array}{l}\text { Amsterdam } \\
\text { Protocol (2013) }\end{array}$ & $\begin{array}{l}\text { International Consensus } \\
\text { on Stool Banking (2019) }\end{array}$ & $\begin{array}{l}\text { Protocol IAG } \\
\text { HC-UFMG }\end{array}$ \\
\hline C. difficile & $\begin{array}{l}\text { PCR for Toxin B, EIA } \\
\text { for Toxins A and B }\end{array}$ & $\begin{array}{l}\text { Toxins (ELISA) and } \\
\text { toxigenic culture }\end{array}$ & $\checkmark$ & GDH + toxigenic culture \\
\hline Adenoviridae & - & - & $\checkmark$ & - \\
\hline Norovirus & - & - & $\checkmark$ & PCR \\
\hline Rotavirus & - & - & $\checkmark$ & PCR \\
\hline Escherichia coli $\mathrm{O} 157$ & - & - & $\checkmark$ & Isolation and PCR \\
\hline $\begin{array}{l}\text { Culture of enteric pathogens } \\
\text { (Salmonella, Shigella, Campylobacter, } \\
\text { Vibrio cholerae, Yersinia) }\end{array}$ & $\checkmark$ & $\checkmark$ & $\checkmark$ & Culture isolation \\
\hline Salmonella sp. (PCR) & - & - & - & Isolation and PCR \\
\hline Clostridium perfringens (PCR) & - & - & - & Isolation and PCR \\
\hline $\begin{array}{l}\text { Microscopy for eggs and parasites } \\
\text { ( } 3 \text { serial samples) }\end{array}$ & $\checkmark$ & $\checkmark$ & $\checkmark$ & $\begin{array}{c}\text { Addition of } \\
\text { Baermann-Moraes }\end{array}$ \\
\hline Giardia lamblia & $\checkmark$ & - & $\checkmark$ & Antigen \\
\hline Entamoeba bistolytica & - & - & - & Antigen \\
\hline Cryptosporidium spp. & $\checkmark$ & - & $\checkmark$ & Microscopy \\
\hline Isospora and Microsporidia & $\checkmark$ & - & $\checkmark$ & Microscopy \\
\hline Helicobacter pylori & - & - & If upper gastrointestinal via & - \\
\hline
\end{tabular}

—, not mentioned; $\checkmark$ recommended; FMT: fecal microbiota transplantation; IAG: Instituto Alfa de Gastroenterologia; HC-UFMG: Hospital das Clínicas, Federal University of Minas Gerais PCR: polymerase chain reaction; EIA: immunoenzymatic assay; ELISA: enzyme-linked immunosorbent assay; GDH: glutamate dehydrogenase; MRSA: methicillin-resistant Staphylococcus aureus; VRE: vancomycin-resistant enterococci; ESBL: expanded-spectrum beta-lactamase producer

possible seroconversion window ${ }^{(41)}$. The International Stool Bank Consensus recommends that donors undergo a full clinical and laboratory evaluation every 8 to 12 weeks $^{(22)}$. It also recommends that the donated feces be subjected to rapid molecular testing for pathogens directly before the infusion or that they remain in quarantine until the donor has undergone a new additional screening at the end of the period and remains eligible ${ }^{(22)}$. The ideal frequency of screening for loyal donors has not been defined. Complete screening is recommended every three to six months or more frequently if the donor becomes symptomatic or if changes in risk factors occur ${ }^{(47)}$.

\section{Challenges in the screening and selection process}

A challenge to maintaining a stool bank is the high rate of patients lost to follow-up due to the significant demand for time in conducting tests and donating stools. This trend was observed in the present study. Observational data from a large US stool bank shows a high dropout rate during the donor screening process. About $23.5 \%$ of 15317 candidates (3599 people) lost track during some stage of the process ${ }^{(86)}$. The real reasons were not explained, but the financial burden and time available are possible related factors. Some places admit financial compensation for the expenses and time demanded in the process. However, the financial compensation for tissue and cell donation is still discussed around the world. In Europe, for example, compensation for donation is not allowed. In the United States, funding is allowed for donation of certain materials such as plasma and sperm. In Brazil, there are no specific regulations on fecal donation. The ordinance of the Ministry of
Health, which regulates the National Transplant System, signs that organ and tissue donors and their legal guardian(s) cannot receive any remuneration or any other type of material compensation or financial by the act of donation ${ }^{(87)}$.

Finding donors and keeping them loyal in a fecal transplant program is a challenging task. A study carried out with the Australian transplant center showed that logistical difficulties, such as frequency of exams and a long follow-up period, represent an impediment for about $40 \%$ of potential donors ${ }^{(39)}$. In addition, only $2 \%-12 \%$ of potential candidates are able to complete all stages of the screening process and initiate donations ${ }^{(88)}$. To avoid shortages and keep the transplant center functioning, it is recommended that recruitment be done on a continuous and regular basis.

Out of six donors approved during the entire selection process, only two remained loyal for more than six months. Problems such as displacement for exams, difficulties at work and loss of follow-up were the main obstacles observed.

\section{Degree of relationship between donor and receiver}

Historically, the first transplants were performed with fecal samples from family members. In the impossibility of recruiting a related donor, receptors received material from unrelated volunteers ${ }^{(89)}$. With the advent of stool banks, an inversion of priority was observed, with an increasingly use of feces from universal voluntary donors ${ }^{(83)}$.

Donors' relatives have the disadvantage of embarrassment during the family approach. Zipursky et al. demonstrated that almost 
a third of the receptors considered the conversation with family members to obtain feces unpleasant ${ }^{(90)}$. In addition, the experience of blood centers shows that the detection of infection in targeted blood donors (relatives or friends) is greater than donations from unrelated volunteers ${ }^{(91)}$. A possible explanation is that relatives and friends, in the desire to help, omit small complaints during the screening.

An advantage with the use of unrelated donors is the possibility of providing material quickly when the treatment is indicated. The process of finding a donor is time-consuming, requires a multiperson approach and significant expenditure on blood and stool tests. Performing the entire screening process among family donors may be impractical depending on the urgency of the transplant. The use of universal donors reduces time and costs related to various stages of selection.

Systematic reviews and meta-analyzes found no significant difference regarding the effectiveness and side effects of FMT when comparing donors related to unrelated volunteers ${ }^{(92-95)}$. Current evidence indicates that the success of FMT does not depend on the degree of kinship of donors. However, there is a preference in the use of universal donors, unrelated, due to standardization, reproducibility, security in screening and better cost-effectiveness ${ }^{(47)}$.

\section{Fresh versus frozen stools}

FMT can be performed by administering freshly collected or frozen fecal samples. To use fresh samples, it is necessary to articulate all logistics between feces collection, material preparation and infusion. It is recommended that the transfer of fresh feces takes place within the first 6 hours after evacuation, and should be stored in hermetically sealed containers at a temperature of $2-8^{\circ} \mathrm{C}^{(15)}$. The difficulties faced in this process led to the use of frozen samples that would be previously prepared and would be readily available when necessary. The main studies using frozen fecal samples show a CDI resolution rate between $71 \%$ to $100 \%{ }^{(46,96-102)}$. A similar rate is found when using fresh stools. Three randomized clinical trials compared the use of fresh and frozen samples and found no significant difference in their primary outcomes ${ }^{(96,99,100)}$. Contrarily, a lower resolution rate was reported in a pilot clinical trial using frozen feces in seven patients affected by $\mathrm{CDI}^{(101)}$. The rate was $71.4 \%$ and can be attributed to episodes of severe CDI, refusal to receive a second transplant and absence of intestinal lavage prior to the procedure ${ }^{(101)}$.

\section{Amount of fecal sample}

There is no consensus on the exact amount of fecal sample needed for transplantation. There is evidence of therapeutic success with $30 \mathrm{~g}$ and $200 \mathrm{~g}$ samples ${ }^{(97,103)}$. The minimum amount of feces with documented therapeutic success is $25 \mathrm{~g}$ for infusion in the lower gastrointestinal tract and $12.5 \mathrm{~g}$ for upper $\operatorname{tract}^{(104)}$. Nonetheless, patients transplanted by CDI obtained better results with the use of larger quantities ${ }^{(93)}$. A systematic review showed a higher risk of therapeutic failure (up to four times) with the use of infusions prepared with less than $50 \mathrm{~g}$ of fecal substrate compared to preparations with more than $50 \mathrm{~g}^{(93)}$.

Regarding the diluent, solutions prepared with sterile saline have a lower recurrence rate, greater reproducibility and standardization during sample preparation ${ }^{(93)}$. Approximately $50 \mathrm{~g}$ (minimum $30 \mathrm{~g}$ ) of fecal substrate is mixed and diluted to $150-250 \mathrm{~mL}$ of sterile $0.9 \%$ saline. The ideal volume is discussed, and preparations between $30 \mathrm{~mL}$ to $500 \mathrm{~mL}$ can be used, with an average of
$250 \mathrm{~mL}^{(104,105)}$. However, there is a higher rate of CDI resolution with administration of larger volumes $(97 \%$ with $500 \mathrm{~mL}, 86 \%$ with $200-500 \mathrm{~mL}$ and $80 \%$ with less than $200 \mathrm{~mL})^{(93)}$. For infusion in the upper route, caution is recommended with the volume administered due to the risk of regurgitation and aspiration pneumonia with larger volumes ${ }^{(105)}$.

\section{Sample processing and storage}

To guarantee the viability of samples it is necessary that they are processed and stored within 6 to 8 hours ${ }^{(106)}$. The fecal microbiota remains stable for up to 8 hours when kept cooled to $4^{\circ} \mathrm{C}^{(107)}$. After this period, there is a gradual reduction in microbial viability related to reduction of its diversity. Freezing in this phase should be avoided as it can disrupt the bacteria structure and affect the quality of samples ${ }^{(108)}$.

The stool processing method differs according to the route of administration. For colonoscopy, whose working channel has a diameter ranging from 2.8 to $3.2 \mathrm{~mm}$, it is necessary that the fecal sample be diluted, homogenized and filtered in order to remove dietary fibers or coarse dirt that may obstruct the canal of the device. After filtration, it is recommended to use cryoprotection with glycerol if the samples are stored under freezing. Cryopreservation is a fundamental step in the creation of a stool bank, as it does not compromise the clinical effect of FMT, prevents the crystallization of the material and allows treatment on demand ${ }^{(96)}$.

The main diluent used is sterile $0.9 \%$ saline. Water, milk, yogurt and saline with psyllium were also used, but without evidence in the literature that favors one in particular ${ }^{(15)}$. Nevertheless, sterile saline is a standard diluent, less likely to interfere with the microbiota. The amount needed varies and depends on the consistency of the stool. In general, $200 \mathrm{~mL}$ of saline solution is used for each $50 \mathrm{~g}$ of stools. The final viscosity of the suspension must be as high as possible to allow adequate passage through the working channel of the colonoscope and remain in the intestine for the longest time ${ }^{(53)}$.

It is not necessary to use an anaerobic chamber to process the samples. In most studies, manipulation occurs under aerobic conditions without impairing the effectiveness of the treatment ${ }^{(46,96-102)}$. However, to avoid overgrowth of aerobic bacteria, the preparation should be as short as possible and the samples should be conducted under refrigeration at $2-8^{\circ} \mathrm{C}$ until final freezing at $-80^{\circ} \mathrm{C}^{(53)}$.

\section{Freezing time and specimen viability}

Another important aspect to be considered with frozen samples is the viability of the microbiota over the storage time. Studies show that storage conditions of fecal samples affect the microbiota composition, although major changes occur after storage at room temperature for more than $24 \mathrm{~h}^{(109,110)}$. Costello et al. evaluated the viability of the microbiota of fecal samples frozen at $-80^{\circ} \mathrm{C}$ for six months of storage and demonstrated that it remains practically unchanged during this period ${ }^{(11)}$. CDI resolution can be achieved with storage time of six months, 10 months and up to one year, with frozen preparations containing glycerol as a cryoprotectant at $-80^{\circ} \mathrm{C}^{(5,46,102,111)}$. Similar results have been reported in animal model studies although a decline in microbiota diversity is observed after seven months of storage ${ }^{(112)}$.

Storing fecal suspensions at $-20^{\circ} \mathrm{C}$ for up to 30 days is also effective in FMT for recurrent CDI. However, at this temperature, the proportion of Firmicutes/Bacteroidetes was significantly higher in fecal samples frozen for more than 50 days compared to fresh samples from the same donor ${ }^{(113)}$. Fecal suspensions can be safely 
maintained at $-20^{\circ} \mathrm{C}$ for up to two months without compromising the effectiveness of treatment ${ }^{(108)}$.

It is recommended that fecal suspensions be stored for up to two years and can be used for transplantation within one year after donation if they have been stored at $-80^{\circ} \mathrm{C}^{(22)}$. After two years the stored material must not be used. It must be disposed of according to the local medical waste management procedure. However, a small aliquot of stool from each donor must be stored to ensure traceability in the event of future adverse events.

\section{Fecal microbiota transplantation indication: recurrent and refractory $C$. difficile infection}

FMT is recommended for the treatment of recurrent CDI, regardless of severity. Patients with at least two previous episodes of CDI undergoing standard antimicrobial treatment and with no sustained cure should be considered for $\mathrm{FMT}^{(47)}$. The recommendation is based on the high rate of symptom resolution achieved with the restoration of a healthy microbiota. In addition to efficacy, FMT has a favorable safety profile that must be considered in the risk-benefit ratio for patients with recurrent CDI. Several studies have shown an excellent safety profile, especially in short-term follow-up, with reports of mild, self-limited and short-term adverse events, such as abdominal discomfort and flatulence ${ }^{(114)}$.

Transplantation can also be indicated as a therapeutic option for refractory CDI. The resolution rate found in observational studies is approximately $55 \%{ }^{(115)}$. Refractory cases appear to have a lower rate of response to FMT. British cohort with 124 patients showed a resolution rate of $91.0 \%$ for recurrent CDI and $73.0 \%$ for refractory CDI on the seventh day $(P=0.007)$. However, at the end of the third month of follow-up, the rates became equivalent $(75.0 \% \text { vs } 82.0 \%, P=0.4)^{(116)}$. In addition, serious and complicated CDI can manifest as refractory infection, with persistence of symptoms despite antimicrobial treatment. In this context, FMT should be considered as an alternative to surgical treatment, especially in cases of severe CDI with early failure to antibiotics ${ }^{(12)}$. FMT should be weighted inclusive in severe-complicated and refractory CDI to the first antimicrobial treatment ${ }^{(47)}$. Mortality from severe and complicated CDI, requiring a colectomy, can reach $80 \%$, especially in cases where surgery is performed late ${ }^{(10)}$. The cure rate for FMT in this scenario is $66-88 \%{ }^{(117)}$. The colonoscopic route was the most used in these cases and some authors maintained the use of vancomycin after the procedure ${ }^{(117)}$. Regarding fulminant CDI, defined as severe CDI accompanied by arterial hypotension or shock, toxic ileus or megacolon that did not respond to the optimized clinical treatment, the FMT being an option to be considered in the subgroup of patients with high surgical risk $^{(22)}$.

An important issue still to be listed is the possibility of transferring a microbiota with harmful characteristics that will manifest after decades ${ }^{(12)}$. Thus, it is recommended that FMT be indicated in clinical practice only for the treatment of conditions in which there is a high level of evidence. Conditions such as inflammatory bowel disease, irritable bowel syndrome, metabolic disorders, hepatobiliary disorders, autism appear as possible clinical indications for FMT, but still with no strong evidence-based recommendation ${ }^{(12)}$. There is also insufficient evidence to recommend FMT as a treatment for the first episode of $\mathrm{CDI}^{(12)}$.

\section{Pre-transplant antibiotics management}

Patients with recurrent CDI should be treated with antibiotics for at least 3 days before FMT in order to reduce the load of $C$. difficile and improve the result with the transplant ${ }^{(12)}$. Vancomycin has been used at a dose of $125-500 \mathrm{mg}$, orally, four times a day for three, five, ten or more days before the procedure ${ }^{(9,18,96)}$. Antimicrobial therapy should be stopped 12-48 hours before infusion of fecal substrate to avoid negative effects on the transplanted microbiota. In emergency cases, when frozen samples are immediately available for transplantation, bridge therapy with antibiotics can be dispensed with ${ }^{(12)}$.

\section{Bowel preparation}

It is not yet clear whether intestinal cleansing is really necessary for the success of FMT. However, even with a low level of evidence, the European Consensus on FMT recommend intestinal preparation with polyethylene glycol (also known as PEG or macrogol) before the procedure, even if the FMT is performed through the upper gastrointestinal or colonoscopic route ${ }^{(11,12)}$. The rationale for this measure is the load reduction capacity of $C$. difficile after intestinal washing ${ }^{(9,118)}$.

Van Nood et al., in a randomized clinical trial, compared three treatment regimens for recurrent CDI: (1) isolated use of vancomycin, (2) vancomycin associated with intestinal cleansing in fourth or fifth day of treatment and (3) FMT by feces infusion via nasoeduodenal tube preceded by a short period of vancomycin (4-5 days) and intestinal cleaning with four liters of macrogol solution $^{(9)}$. Thirteen of the $16(81 \%)$ patients achieved CDI resolution after the first FMT and two of the remaining three after a second infusion, resulting in an overall success rate of $94 \%$. The resolution of CDI in the other two groups was significantly lower. In patients treated with vancomycin alone, four out of $13(31 \%)$ achieved CDI resolution. In the group that received vancomycin with intestinal cleansing, only three of the $13(23 \%)$ patients. Intestinal cleansing, as an isolated intervention, was not effective in resolving CDI. On the other hand, associated with FMT, it caused a cure rate of up to $94 \%$.

Lee et al., in a randomized clinical trial, evaluated FMT via enema using fresh frozen feces to treat recurrent CDI without colonic preparation ${ }^{(96)}$. Similar to other studies, patients received suppressive treatment with antibiotics that were interrupted 24 to 48 hours before transplantation. No preparation was used before applying the enemas. Even without intestinal cleansing, the success rate achieved was $83.5 \%$ with frozen stools and $85.1 \%$ with fresh stools.

Fischer et al., in a retrospective multicenter study, evaluated the effectiveness of FMT according to intestinal preparation. Among the 413 patients undergoing FMT via colonoscopy, the quality of preparation was classified as excellent, regular and poor in $67 \%$, $22 \%$ and $11 \%$ respectively ${ }^{(119)}$. Among those who did not respond to FMT, $15 \%$ had adequate preparation, $24 \%$ regular and $35 \%$ poor $(P=0.003$, univariate analysis). However, after including other risk factors for therapeutic failure in the analysis (severity of CDI, hospitalization and previous number of CDI), the variable intestinal cleansing did not persist in the final model of the multivariate analysis. Compared to the group of patients with adequate bowel preparation, the odds ratio for FMT failure was $1.16(95 \%$ CI: $0.57-2.37 ; P=0.68)$ for regular preparation and $1.64(95 \% \mathrm{CI}$ : $0.69-3.88 ; P=0.26$ ) for poor.

Intestinal cleaning is safe and allows an adequate study of the ileocolonic mucosa. However, it is capable of promoting changes in the microbiota with a substantial reduction in microbial load by up to 31 times $^{(118)}$. It also considerably alters its composition, with 
loss of individual microbial specificity in up to $22 \%$ of patients undergoing intestinal preparation with polyethylene glycol $^{(118)}$. Yet, 14 days after bowel preparation, the microbiota of these individuals recover, resembling their original form ${ }^{(118)}$.

There are several purgatives that can be used in intestinal cleansing. Polyethylene glycols are non-absorbable isosmotic solutions, with an excellent safety profile, which pass through intestine without absorption or liquid secretion, with minimal impact on the volume or electrolyte composition of patients. The preparations must be diluted in large volumes of water (up to 4 liters) to obtain the desired cathartic effect. Compliance is best with split dose regimens, with 2 liters the day before the exam (usually at night) and 2 liters the next morning (specifically for exams in the afternoon). Due to its safety profile, it can be used even in patients with chronic kidney disease, anuric, on hemodialysis ${ }^{(120)}$.

\section{Rote of administration}

FMT can be performed by inserting a nasoenteric, nasogastric tube, via gastroduodenoscope, enteroscope, by capsules containing lyophilized material, by colonoscopy, sigmoidoscopy or retention enemas. There is no method that is proven to be more effective than another. The choice depends on the particularities of each patient and the logistics of the transplant center. A study that compared the efficacy of the upper to the lower route found no significant difference between them. The success rate using the upper route was $88 \%$ (95\% CI: $0.82-0.94)$ compared to $95 \%$ (95\% CI: $0.92-0.97)$, using the lower $(P=0.162)^{(121)}$. All routes are effective for the treatment of recurrent CDI with numerical advantage, but not statistically significant, in relation to colonoscopy ${ }^{(92,122)}$. A recent systematic review showed that the majority of adult underwent FMT via colonoscopy $(42 \%)$ followed by gastric or duodenal application $(22 \%)$, enema $(12 \%)$ or a combination of two methods $(11 \%)^{(15)}$.

Colonoscopy is considered by many to be the gold stand$\operatorname{ard}^{(98,123)}$. It has the advantage of the ability to visualize the colon and the possibility of infusing the material in the most affected intestinal segments, especially in the proximal colon, where the involvement by pseudomembranes is usually more severe ${ }^{(124)}$. Besides that, it is more physiological, allows the administration of a greater amount of feces, which would be related to the higher success rate found in some studies ${ }^{(125)}$. However, it has the drawback of intestinal lavage and the risk of perforation inherent in the procedure.

Fecal enemas are less invasive, easy to perform, cheaper and can be performed in an outpatient setting ${ }^{(126)}$. As a disadvantage, there is a shorter stool retention time, particularly in patients with sphincter hypotonia, a lower reach of the substrate in the colon (up to splenic flexure) and the need for multiple procedures to obtain efficacy ${ }^{(17)}$.

The upper routes are fast and less expensive when compared to colonoscopy. Notwithstanding, they are aesthetically unpleasant and uncomfortable, especially the nasoenteric tubes where it is possible to monitor the infusion of fecal material through the tube. To avoid regurgitation, a smaller volume is used, which can compromise the final result of the transplant ${ }^{(125)}$. Another concern is the degradation of the microbiota due to gastric acidity and the possibility of serious complications such as bronchoaspiration, hemorrhage and gastrointestinal perforation ${ }^{(127)}$ Wang et al., in a systematic review, demonstrated that the rate of adverse events with upper route administration was higher in relation to the lower $(43.6 \% \text { and } 17.17 \% \text { respectively })^{(114)}$. The most serious side effects associated with FMT were reported via upper gastrointestinal tract, due to the risk of vomiting and aspiration. Three deaths related to FMT occurred after application to the upper tract, two cases of aspiration pneumonia and one case of septic shock secondary to toxic megacolon $^{(128-130)}$. Cases of non-lethal aspiration pneumonia after vomiting of fecal suspension and a small intestinal abscess with nasojejunal route have also been reported ${ }^{(131)}$.

There is also the possibility of FMT by enteroscopy. Ganc et al., in 2015, published a successful Brazilian experience of 12 patients who underwent FMT by endoscopic infusion in the proximal jejunum. The resolution rate was similar to that described by other routes $^{(36)}$. The endoscopic route, whether superior or inferior, should be performed only by trained endoscopists to reduce the risk of complications ${ }^{(22)}$. There is no data available on the FMT learning curve, but the opinion of experts is that professionals should perform at least ten transplants before being considered trained ${ }^{(22)}$. Capsules appear as a promising option for dispensing intestinal preparation and hospitalization. They are more aesthetically pleasing, less invasive and eliminate the risk of endoscopic perforation. However, they need technology for lyophilization and preparation of capsules resistant to gastric acidity. The lyophilization process is expensive and consists of production of powder substrate from the vacuum drying of fecal suspensions ${ }^{(132)}$. The rate of CDI resolution with capsules is similar to rates through the use of colonoscopy. Conversely, it presents as a limiting factor, the need to ingest a high number of capsules throughout the day (minimum of 30 capsules per day in some studies) ${ }^{(133)}$. In the short term, new technologies will most probably be incorporated and this procedure could occupy a prominent place.

\section{Post-procedure care}

Patients undergoing colonic FMT can receive loperamide, usually $2-4 \mathrm{mg}$, to reduce intestinal transit time and improve colonization conditions of the microbiota ${ }^{(53)}$. It is also recommended that patients remain in the right lateral decubitus position or in Trendelenburg to increase the retention time of the transplanted fecal material ${ }^{(53)}$. But there are few studies that describe this recommendation, based only on expert opinion. There are no studies proving the effectiveness of its use.

\section{Number of transplants}

A second FMT may be required in case of failure or recurrence after the first attempt ${ }^{(134)}$. In severe CDI, especially in colitis with endoscopic evidence of pseudomembranes, repeated fecal transplants may be necessary ${ }^{(12)}$. Among outpatients with recurrent CDI, a single colonoscopy infusion has a cure rate of 85 to $91 \%$ while patients with severe or complicated CDI can achieve an equally high cure rate from repeated courses of antibiotics and fecal infusion ${ }^{(135)}$. Most patients achieve CDI cure with one or two FMT combined with vancomycin and only a minority require three or more ${ }^{(135)}$.

Cammarota et al. successfully treated patients with pseudomembranous colitis from colonoscopy infusions every 3 days ${ }^{(18)}$. However, to achieve a high success rate, an average of two to three procedures per patient was required.

Fischer et al. demonstrated that leukocytosis (count above 22.6 $\mathrm{x} 10^{3}$ cells $/ \mathrm{mm}^{3}$ ), hypoalbuminemia (serum albumin below $2.3 \mathrm{mg} /$ $\mathrm{dL}$ ), presence of pseudomembranes at the first colonoscopy and use of antibiotics for other infections (non-CDI) are predictive factors for new transplants. The presence of pseudomembranes and the use of other antibiotics increase the chance of a new procedure by six and three times respectively. In the study, $47.4 \%$ of patients required two or more transplants. Only one required five infusions ${ }^{(135)}$. 


\section{Traceability}

The entire process involved in the FMT must be carried out and monitored with strict quality control. From the inclusion of donors to the administration of fecal substrate it is necessary to take measures to ensure a high standard of quality and complete traceability. Measures include education of the personnel involved, validation of laboratory procedures and equipment, and recording of information. Donor data, laboratory tests, fecal samples should be stored for up to 10 years to ensure traceability. It is advisable to store fecal samples from receptors before and after transplantation, as well as donors to allow follow-up in case of future adverse effects ${ }^{(47)}$

\section{Adverse events and safety}

FMT is considered a safe, well-tolerated therapeutic method with few adverse events (AE), generally self-limited and shorttermed $^{(136)}$. Most clinical trials and systematic reviews show that AE related to FMT are minor events, observed transiently after procedure and with short-term spontaneous resolution. The main ones are diarrhea, abdominal discomfort, constipation and fever. Severe events are uncommon and are often associated with complications related to sedation or endoscopic procedure ${ }^{(9,11,16,99,127)}$.

Wang et al., in a systematic review with 1089 patients, found occurrence of AE in $28.5 \%$ of fecal transplants ${ }^{(114)}$. There was a higher rate of $\mathrm{AE}$ in patients undergoing FMT through the upper gastrointestinal tract $(43.6 \%)$ compared to the lower tract $(17.7 \%)$. However, the occurrence of severe events was $2.0 \%$ in high route and $6.1 \%$ in low route. The main ones related to the upper way were abdominal pain, nasal congestion, sore throat, rhinorrhea and gastrointestinal bleeding. Abdominal discomfort followed by transient fever was the most common event in both routes. Patients with inflammatory bowel disease had more fever than those with CDI (7.9\% vs $2.0 \%, P=0.011)$. A total of 44 severe AE occurred in $9.2 \%$ of the patients being death $(3.5 \%, 38 / 1089)$, infection $(2.5 \%$, $27 / 1089)$ and reactivation of inflammatory bowel disease $(0.6 \%$, $7 / 1089$ ). However, of the 38 deaths, only one was definitively related to FMT (bronchoaspiration during colonoscopy sedation) and two possibly related (pneumonia and peritonitis three days after FMT by nasogastric tube). Regarding the incidence of severe infection, eight cases were probably or possibly related and 19 unrelated. Of the eight infections, two were viral (cytomegalovirus and norovirus), two bacterial (Escherichia coli, Proteus mirabilis, Citrobacter koseri, and Enterococcus faecium) and four without identified pathogen ${ }^{(114)}$.

Lai et al., in an analysis of 5958 patients submitted to FMT since 2014, found a general incidence of adverse events of less than $1 \%{ }^{(52)}$. The most common AEs were diarrhea $(13.0 \%)$, distension/ flatulence (11.6\%), nausea/vomiting (6.1\%), abdominal pain $(5.5 \%)$ constipation $(2.1 \%)$, fever $(2.7 \%)$, headache $(1.5 \%)$ and fatigue $(1.4 \%)$. Severe AE were: aspiration pneumonia $(0.16 \%)$, death $(0.13 \%)$, sepsis $(0.07 \%)$, intestinal perforation $(0.07 \%)$, hospitalization $(0.02 \%)$ and sedation-related complications $(0.02 \%)^{(52)}$.

FMT was shown to be safe in an immunosuppressed population with recurrent CDI. Shogbesan et al., in systematic review with 303 patients, most due to the use of immunosuppressive drugs, presented severe AE rate similar to immunocompetent patients. Nineteen $(0.06 \%)$ patients had serious adverse (two deaths, two cholectomies, five infections, 10 hospitalizations). Twenty-eight (9.24\%) patients had minor AE such as abdominal pain, irritable bowel syndrome, nausea, and transient fever. There was no higher occurrence of infectious adverse events ${ }^{(136)}$. A clinical study on FMT in patients with moderate to severe ulcerative colitis, with follow-up time of up to five years, showed the occurrence of transplantation-related $\mathrm{AE}$ in $17.5 \%$ of cases, most of which were minor and short-term events. Most participants were on immunosuppressive therapy and received FMT by upper rout. Among the 57 reported AE, the main ones were fever, increased evacuatory frequency and abdominal pain during the first six hours ${ }^{(137)}$.

In March 2020, the FDA issued a warning about the risk of severe infection with the use of FMT after notification of six patients who received fecal substrate from the U.S. feces bank for CDI treatment. Two patients developed infection caused by enteropathogenic Escherichia coli (EPEC) and four by shiga toxin-producing Escherichia coli (STEC). Four of the six patients required hospitalization. Two patients who developed EPEC infection received fecal substrate from two different donors. Four patients who developed STEC infection received the product from a single donor ${ }^{(138)}$. Previously, Azimirad et al. described two cases of immunosuppressed patients submitted to FMT because of CDI and who developed infection by Clostridium perfringens enterotoxigenic approximately two months after procedures ${ }^{(139)}$. This finding reinforces the need to include the $C$. perfringens enterotoxigenic during donor screening.

In 2019, the FDA issued a warning about the risk of transmission of multidrug-resistant organisms. Two immunosuppressed adults submitted to FMT developed severe infection by E. coli ESBL, and one died. The material used in both procedures was obtained from the same donor, not tested for the presence of such bacteria. Until then, the research of MDRO had not been routinely performed in transplant centers. After the incident, the FDA issued a recommendation to investigate in donors risk factors related to colonization and direct research of methicillin-resistant Staphylococcus aureus, vancomycin-resistant enterococci, enterobacteriaceae ESBL and carbapenem-resistant Enterobacteriaceae ${ }^{(140)}$.

After the warning from the FDA, the news of the death gained great repercussion in the media and scientific community. However, before the event, at least four deaths had already been described definitively or probably related to transplantation for recurrent CDI. First in an 88-year-old patient, with chronic obstructive pulmonary disease and atherosclerosis, who died 14 days after transplantation via nasogastric tube due to aspiration pneumonia $^{(130)}$. Second death in an immunosuppressed patient, after solid organ transplantation, with cachexia due to advanced esophageal neoplasia, who died one day after FMT via colonoscopic due to bronchoaspiration during sedation ${ }^{(141)}$. Third patient, 68 years old, diabetic and with advanced oropharyngeal neoplasia, feeding by nasogastric tube, received transplant via tube and evolved on the third day with toxic megacolon, septic shock and death ${ }^{(131)}$. Fourth patient, 80 years old, previous history of vasculopathy, osteoarthritis and gout, evolved with septic shock by E. coli secondary to aspiration pneumonia and death after FMT via enteroscopic and under general anesthesia ${ }^{(142)}$.

Patients submitted to FMT should be monitored for adverse events that can be attributed to the procedures. All AE potentially related to FMT must be registered. In addition to infections, the possibility of transmission of a phenotype associated with microbiota should be evaluated in the long term. Even though it is considered a safe method, the risks and therapeutic options should be discussed with the recipient before the procedure. A long-term study on FMT safety (10-year period) is currently underway, which will provide further clarification on the potential risk of developing such conditions ${ }^{(143)}$. 


\section{Cost-effectiveness}

In Brazil there are no epidemiological data on operating costs related to recurrent CDI. Nor comparative studies on costeffectiveness of FMT. Based on international studies, it is known that CDI generates great burden on the health system with annual expenditures estimated at about $\$ 6.3$ billion in the United States and cost per episode of CDI ranging from $€ 5798$ to $€ 11202$ in Europe ${ }^{(144,145)}$. An American cost-effective analysis compared three modalities of FMT (by colonoscopy, duodenal infusion and enema) versus standard antibiotic therapy (metronidazole, vancomycin and fidaxomycin) for the treatment of recurrent $\mathrm{CDI}^{(146)}$. The initial treatment of recurrent CDI with FMT via colonoscopy was the most economical strategy, with a cost-effectiveness rate of US\$17,016 in relation to oral vancomycin. The same trend was observed when compared to metronidazole and fidaxomicin. It also concluded that, in places where FMT is not available, the strategy with oral vancomycin is preferable.

\section{Microbiota after transplantation}

Chang et al. demonstrated that after first episode of CDI the intestinal microbiota is little altered, remaining with predominance of dominant phylums Firmicutes and Bacteroidetes. Nonetheless, after recurrent episodes of CDI, there is a marked reduction in Bacteroidetes accompanied by a marked increase in other phylums that are usually a minority in intestinal microbiota ${ }^{(147)}$. Fecal transplantation reestablishes the initial microbial composition by promoting sustained alteration of the receptor microbiota, with a significant increase in the Firmicutes and Bacteroidetes and reduction of Proteobacteria and Actinobacteria ${ }^{(148)}$.

Khoruts et al. compared the microbiota of a patient with recurrent CDI before and post-FMT. Prior to transplantation, the microbiota presented reduction of Bacteroidetes and increase in atypical bacterial populations such as Veillonella, Clostridium, Lactobacillus, Streptococcus. Two weeks after the infusion of fecal suspension, bacterial composition changed, becoming similar to that of the donor, characteristically marked by diversity, with predominance of Bacteroidetes ${ }^{(149)}$.

$\mathrm{Li}$ et al. evaluated the composition of fecal microbiota after FMT in patients with metabolic syndrome undergoing autologous and allogeneic transplantation. They observed that the donor strains persisted for a period of three months replacing or coexisting alongside recipient strains. Colonization success was higher for species common to the donor and receptor than in relation to the new species inserted. In addition, receptors from the same donor exhibited varying degrees of microbiota transfer, indicating individual patterns of colonization and donor-recipient compatibility ${ }^{(150)}$. Another study on microbiota recovery in recurrent CDI showed that FMT significantly alters the microbiota in the long term and that the phylogenetic profile of the recipient is similar to that of the donor for up to one year ${ }^{(136)}$.

\section{Patient's view of fecal transplantation}

FMT faces cultural issues that may hinder its acceptance. It is speculated that there is a low receptivity to treatment, justified in part, by its unpleasant nature. Nevertheless, studies on patient acceptance show that up to $94 \%$ of them would choose to receive FMT if it was required ${ }^{(90)}$.

Patients with recurrent CDI experienced prolonged suffering with a debilitating disease, multiple hospitalizations and use of poorly palatable oral medications. Although culturally unpleasant, patients make a favorable judgment between recurrence risk and potential risks/benefits of FMT. Family support and educational level are also considered significant predictors of acceptance, particularly among married people, with children and those with higher education $^{(151)}$.

Even so, a small proportion of patients refuse treatment. One of the barriers is the "yuck factor" described as negative instinctive reaction in relation to a treatment considered dirty or unpleasant. However, the main factor of refusal is concern with the safety, especially the fear of disease transmission. Another factor is aversion to certain routes of administration, especially those using nasoenteric probes and the oral route. There is preference for the administration of fecal substrate directly in the colon, through colonoscopy. But the idea of ingesting odorless capsule is also well accepted ${ }^{(5,90)}$.

Interestingly, physicians who treat patients with recurrent CDI can also act as a barrier to the FMT indication, either due to lack of knowledge, limited experience, safety concerns, institutional and logistical barriers or concern about patient receptivity. An American study on the attitude of physicians towards FMT shows that almost a third of them did not indicate treatment in recurrent CDI because they believed that there would be a refusal by patients ${ }^{(90)}$. What is observed, however, is that there is a clear disagreement between the beliefs of physicians and their patients. The health professional plays an important role in the clarification and education of their patients. The involvement of both parties in the process of choosing a treatment is decisive for its acceptance.

\section{CONCLUSION}

Fecal microbiota transplantation has been considered a standard treatment for patients with recurrent or refractory $C$. difficile infection. Studies indicate that FMT is an effective therapeutic option, with a favorable risk-benefit ratio, in patients with failure to conventional antimicrobial treatment. Although transplantation appears to be safe, with few adverse effects, there is a theoretical risk of transmission of dysbiosis-related phenotypes. Long-term security data are needed to guide donor selection and rationalize interventions in the microbiota. In addition, many concepts on dysbiosis and microbiota manipulation are still under construction and their better understanding will provide subsidies for the use of a more effective and personalized treatment.

Recent identification of hypervirulent ribotype 027 and strains producing binary toxin in Brazil raises the warning about the need to optimize methods to face CDI. Incentives in health policies are necessary to expand the diagnostic and therapeutic capacity of a condition responsible for major epidemics in recent decades. The creation of a platform like the one presented, capable of providing treatment to serious and recurrent cases, is fundamental in addressing a growing condition in the country.

Fecal microbiota transplantation is a treatment modality under investigation. Thus, it needs scientific and ethical support for its application in daily clinical practice. It should be carried out in a research environment, in centers with experience in the CDI treatment and with the approval of local ethics committee, especially for conditions beyond of CDI, whose evidence on benefit is still scarce. Its use outside these molds should be discouraged in Brazil.

The structuring of a Fecal Microbiota Transplant Center with a frozen stool bank allowed access to an innovative treatment 
modality that is not widely available in the country. Transplant centers with a stool bank allow to perform treatment on demand, less personalized, with more security and traceability. In addition, it allows standardization in the selection and manipulation of fecal samples, better evaluation of interventions, comparison of results and facilitates scientific communication.

Donor selection is a vital step in structuring a transplant center. However, finding healthy donors and keeping them loyal is a challenging task. This selection protocol used broad clinical criteria and was able to identify a large number of clinical contraindications prior to blood and stool tests. Our rigorous evaluation allowed us to identify contraindications in potential donors and rationalize the use of resources.

This article, as far as we know, was the first study to describe the experience in implementing a unit on fecal microbiota transplantation in Brazil. He sought to describe detailed instructions for structuring a fecal transplant center, such as regulatory and ethical aspects, selection of donors, processing and storage of samples, route of administration and post-procedure follow-up. The implantation steps described here should facilitate the safe dissemination of fecal transplant centers in emerging countries.

\section{ACKNOWLEDGEMENTS}

This study was supported by CNPq, Capes/Proex, Fapemig, PRPq-UFMG, and Graduate Program in Sciences Applied to Adult Health at UFMG. The authors are grateful for the partnership with the Department of Digestive Endoscopy at HC-UFMG and Bacteriosis Laboratory of the Department of Preventive Veterinary Medicine at UFMG.

\section{Authors' contribution}

Terra DAA: study conception, planned FMT service, donor selection, clinical patient management, colonoscopies, data collection, statistical analysis and manuscript writing. Vilela EG: study conception, planned FMT service, statistical analysis and manuscript review. Silva ROS: study conception, planned FMT service, data collection, performed diagnostic and laboratory tests on donors and patients. Leão LA, Lima KS and Passos RIFA: data collection, processing of biobank samples and routines. Diniz AN: data collection and performed diagnostic and laboratory tests on donors and patients. Coelho LGV: study conception, planned and coordinated the FMT service, manuscript review.

\section{Orcid}

Daniel Antônio de Albuquerque Terra: 0000-0001-9691-6512.

Eduardo Garcia Vilela: 0000-0002-5443-7553.

Rodrigo Otávio Silveira Silva: 0000-0003-0074-2488.

Laiane Alves Leão: 0000-0001-6547-3798.

Karine Sampaio Lima: 0000-0001-8897-3410.

Raissa Iglesias Fernandes Ângelo Passos: 0000-0003-0705-5568.

Amanda Nádia Diniz: 0000-0002-5287-5779.

Luiz Gonzaga Vaz Coelho: 0000-0002-8721-7696.

Terra DAA, Vilela EG, Silva ROS, Leão LA, Lima KS, Passos RIFA, Diniz AN, Coelho LGV. Estruturação de centro de transplante de microbiota fecal em hospital universitário no Brasil. Arq Gastroenterol. 2020;57(4):434-58.

RESUMO - Contexto - O Transplante de microbiota fecal (TMF) é uma importante opção terapêutica para a infecção recorrente ou refratária pelo Clostridioides difficile, sendo método seguro e eficaz. Resultados iniciais sugerem que o TMF também desempenha papel relevante em outras afecções cuja patogênese envolve a alteração da microbiota intestinal. No entanto, seu uso sistematizado é pouco difundido, especialmente no Brasil. Na última década, surgiram múltiplos relatos e séries de casos utilizando diferentes protocolos para o TMF, sem padronização de métodos e com taxas de resposta variáveis. No Brasil, poucos casos isolados de TMF foram relatados sem a implantação de um Centro de Transplante de Microbiota Fecal (CTMF). Objetivo - O principal objetivo deste estudo foi descrever o processo de implantação de um CTMF com banco de fezes, em hospital universitário brasileiro, para tratamento de infecção recorrente e refratária pelo $C$. difficile. Métodos - O CTMF foi estruturado dentro dos critérios exigidos e aprovados por organismos internacionais como o Food and Drug Administration, Grupo Europeu de Transplante de Microbiota Fecal e em consonância com os aspectos epidemiológicos e regulatórios nacionais. Resultados - Foi estabelecida toda uma plataforma envolvida na estruturação de um centro de transplante com fezes congeladas. Determinou-se os critérios para seleção de doadores, processamento e armazenamento de amostras, manejo dos receptores antes e após o procedimento, uniformização de vias de administração do substrato fecal e seguimento a curto e longo prazo dos pacientes transplantados. A seleção dos doadores foi conduzida em três etapas: pré-triagem, avaliação clínica e exames laboratoriais. Boa parte dos candidatos foram excluídos na primeira $(75,4 \%)$ e segunda etapa $(72,7 \%)$. Os principais critérios clínicos de exclusão foram: diarreia aguda recente, excesso de peso (IMC $\geq 25 \mathrm{~kg} / \mathrm{m}^{2}$ ) e distúrbios gastrointestinais crônicos. Quatro dos 134 candidatos foram selecionados após a triagem completa, com taxa de detecção de doadores de 3\%. Conclusão - A implantação de um CTMF, inédito no nosso meio, possibilita o acesso de pacientes com infecção recorrente e refratária pelo $C$. difficile a tratamento inovador, seguro, com elevada taxa de sucesso e pouco disponível no Brasil. A seleção apropriada de doadores qualificados é vital no processo de implantação de um CTMF. A avaliação clínica rigorosa dos doadores permitiu o uso racional de recursos para realização de exames laboratoriais. Um CTMF possibilita tratamento sob demanda, em maior escala, menos personalizados, com mais segurança e rastreabilidade. Este protocolo fornece subsídios para a realização de TMF em países emergentes.

DESCRITORES - Transplante de microbiota fecal. Infecções por Clostridium. Microbiota. Microbioma gastrointestinal. Diarreia. Fezes. 


\section{REFERENCES}

1. Milani C, Duranti S, Bottacini F, Casey E, Turroni F, Mahony J, et al. The First Microbial Colonizers of the Human Gut: Composition, Activities, and Health Implications of the Infant Gut Microbiota. Microbiol Mol Biol Rev. 2017;81(4):e0036-17. doi:10.1128/MMBR.00036-17.

2. Peterson J, Garges S, Giovanni M, McInnes P, Wang L, Schloss JA, et al. The NIH Human Microbiome Project. Genome Res. 2009;19(12):2317-23. doi:10.1101/ gr.096651.109.

3. Bojanova DP, Bordenstein SR. Fecal Transplants: What Is Being Transferred? PLoS Biol. 2016;14(7):e1002503. doi:10.1371/journal.pbio.1002503.

4. Mamo Y, Woodworth MH, Wang T, Dhere T, Kraft CS. Durability and Long-term Clinical Outcomes of Fecal Microbiota Transplant Treatment in Patients With Recurrent Clostridium difficile Infection. Clin Infect Dis. 2018;66(11):1705-11. doi:10.1093/cid/cix1097

5. Youngster I, Mahabamunuge J, Systrom HK, Sauk J, Levin J, Kaplan JL, et al. Oral, frozen fecal microbiota transplant (FMT) capsules for recurrent Clostridium difficile infection. BMC Med. 2016;14(1):134. doi:10.1186/s12916-016-0680-9.

6. Zhang F, Luo W, Shi Y, Fan Z, Ji G. Should we standardize the 1,700-year-old fecal microbiota transplantation?. Am J Gastroenterol. 2012;107(11):1755-p.1756. doi:10.1038/ajg.2012.251

7. Lewin RA. Merde: Excursions in Scientific, Cultural, and Socio-Historical Coprology. New York: Random House Inc; 1999.

8. Eiseman B, Silen W, Bascom GS, Kauvar AJ. Fecal enema as an adjunct in the treatment of pseudomembranous enterocolitis. Surgery. 1958;44(5):854-59.

9. van Nood E, Vrieze A, Nieuwdorp M, Fuentes S, Zoetendal EG, de Vos WM, et al. Duodenal infusion of donor feces for recurrent Clostridium difficile. N Engl J Med. 2013;368(5):407-15. doi:10.1056/NEJMoa1205037.

10. McDonald LC, Gerding DN, Johnson S, et al. Clinical Practice Guidelines for Clostridium difficile Infection in Adults and Children: 2017 Update by the Infectious Diseases Society of America (IDSA) and Society for Healthcare Epidemiology of America (SHEA). Clin Infect Dis. 2018;66(7):e1-e48. doi:10.1093/ $\mathrm{cid} / \mathrm{cix} 1085$

11. Haifer C, Kelly CR, Paramsothy S, Andresen D, Papanicolas LE, McKew GL, et al. Australian consensus statements for the regulation, production and use of faecal microbiota transplantation in clinical practice. Gut. 2020;69(5):801-10. doi:10.1136/gutjnl-2019-320260.

12. Cammarota G, Ianiro G, Tilg H, Rajilić-Stojanović M, Kump P, Satokari R, et al. European consensus conference on faecal microbiota transplantation in clinical practice. Gut. 2017;66(4):569-80. doi:10.1136/gutjnl-2016-313017.

13. Hocquart M, Lagier JC, Cassir N, Saidani N, Eldin C, Kerbaj J, et al. Early Fecal Microbiota Transplantation Improves Survival in Severe Clostridium difficile Infections. Clin Infect Dis. 2018;66(5):645-50. doi:10.1093/cid/cix762.

14. Panchal P, Budree S, Scheeler A, Medina G, Seng M, Wong WF, et al. Scaling Safe Access to Fecal Microbiota Transplantation: Past, Present, and Future [published correction appears in Curr Gastroenterol Rep. 2018 Jun 8;20(7):28. Eliott R [corrected to Elliott R]]. Curr Gastroenterol Rep. 2018;20(4):14. doi:10.1007/ s11894-018-0619-8

15. Sha S, Liang J, Chen M, Xu B, Liang C, Wei N, et al. Systematic review: faecal microbiota transplantation therapy for digestive and nondigestive disorders in adults and children. Aliment Pharmacol Ther. 2014;39(10):1003-32. doi:10.1111/ apt.12699.

16. Rossen NG, MacDonald JK, de Vries EM, D'Haens GR, de Vos WM, Zoetendal $\mathrm{EG}$, et al. Fecal microbiota transplantation as novel therapy in gastroenterology: A systematic review. World J Gastroenterol. 2015;21(17):5359-71. doi:10.3748/ wjg.v21.i17.5359

17. Brandt LJ, Aroniadis OC, Mellow M, Kanatzar A, Kelly C, Park T, et al. Longterm follow-up of colonoscopic fecal microbiota transplant for recurrent Clostridium difficile infection. Am J Gastroenterol. 2012;107(7):1079-87. doi:10.1038/ ajg.2012.60.

18. Cammarota G, Masucci L, Ianiro G, Bibbò S, Dioni G, Costamagna G, et al. Randomised clinical trial: faecal microbiota transplantation by colonoscopy vs. vancomycin for the treatment of recurrent Clostridium difficile infection. Aliment Pharmacol Ther. 2015;41(9):835-43. doi:10.1111/apt.13144.

19. Pinn DM, Aroniadis OC, Brandt LJ. Is fecal microbiota transplantation (FMT) an effective treatment for patients with functional gastrointestinal disorders (FGID)?. Neurogastroenterol Motil. 2015;27(1):19-29. doi:10.1111/nmo.12479.

20. Spring S, Services H. U.S. Food and Drug Administration. 2013. Guidance for industry: enforcement policy regarding investigational new drug requirements for use of fecal microbiota for transplantation to treat Clostridium difficile infection not responsive to standard therapie. (March 2016).

21. Kelly CR, Kunde SS, Khoruts A. Guidance on preparing an investigational new drug application for fecal microbiota transplantation studies. Clin Gastroenterol Hepatol. 2014;12(2):283-8. doi:10.1016/j.cgh.2013.09.060.
22. Cammarota G, Ianiro G, Kelly CR, Mullish BH, Allegretti JR, Kassam Z, et al. International consensus conference on stool banking for faecal microbiota transplantation in clinical practice. Gut. 2019;68(12):2111-21. doi:10.1136/gutjnl-2019-319548.

23. Oren A, Rupnik M. Clostridium difficile and Clostridioides difficile: Two validly published and correct names. Anaerobe. 2018;52:125-6. doi:10.1016/j.anaerobe.2018.07.005

24. Lessa FC, Mu Y, Bamberg WM, Beldavs ZG, Dumyati GK, Dunn JR, et al. Burden of Clostridium difficile infection in the United States. N Engl J Med. 2015;372(9):825-34. doi:10.1056/NEJMoa1408913.

25. McDonald LC, Killgore GE, Thompson A, Owens RC, Kazakova SV, Sambol $\mathrm{SP}$, et al. An epidemic, toxin gene-variant strain of Clostridium difficile. N Engl J Med. 2005;353(23):2433-41. doi:10.1056/NEJMoa051590.

26. Dudukgian H, Sie E, Gonzalez-Ruiz C, Etzioni DA, Kaiser AM. C. difficile colitis--predictors of fatal outcome. J Gastrointest Surg. 2010;14(2):315-22. doi:10.1007/s11605-009-1093-2

27. Dallal RM, Harbrecht BG, Boujoukas AJ, Cirio CA, Farkas LM, Lee KK, et al. Fulminant Clostridium difficile: an underappreciated and increasing cause of death and complications. Ann Surg. 2002;235(3):363-72. doi:10.1097/00000658200203000-00008

28. Kelly CP. Can we identify patients at high risk of recurrent Clostridium difficile infection?. Clin Microbiol Infect. 2012;18 Suppl 6:21-27. doi:10.1111/14690691.12046.

29. Silva ROS, Junior CAO, Diniz AN, Alves GG, Guedes RMC, Vilela EG, et al. Antimicrobial susceptibility of Clostridium difficile isolated from animals and humans in Brazil. Cienc. Rural [online]. 2014;44(5): 841-6. Available from: <http:// www.scielo.br/scielo.php?script=sci_arttext\&pid=S0103-84782014000500013\&l$\mathrm{ng}=\mathrm{en} \& \mathrm{nrm}=\mathrm{iso}>$

30. Seekatz AM, Aas J, Gessert CE, Rubin TA, Saman DM, Bakken JS, Young VB. Recovery of the gut microbiome following fecal microbiota transplantation. mBio. 2014;5(3):e00893-14. doi:10.1128/mBio.00893-14.

31. Theriot CM, Young VB. Microbial and metabolic interactions between the gastrointestinal tract and Clostridium difficile infection. Gut Microbes. 2014;5(1):86-95. doi:10.4161/gmic. 27131

32. Ott SJ, Waetzig GH, Rehman A, Moltzau-Anderson J, Bharti R, Grasis JA, et al. Efficacy of Sterile Fecal Filtrate Transfer for Treating Patients With Clostridium difficile Infection. Gastroenterology. 2017;152(4):799-811.e7. doi:10.1053/j. gastro.2016.11.010.

33. Trindade CNR, Domingues RMCP, Ferreira EO. The epidemiology of Clostridioides difficile infection in Brazil: A systematic review covering thirty years. Anaerobe. 2019;58:13-21. doi: 10.1016/j.anaerobe.2019.03.002.

34. Lopes Cançado GG, Silveira Silva RO, Rupnik M, Nader AP, Starling de Carvalho J, Paixão GMM, et al. Clinical epidemiology of Clostridium difficile infection among hospitalized patients with antibiotic-associated diarrhea in a university hospital of Brazil. Anaerobe. 2018;54:65-71. doi:10.1016/j.anaerobe. 2018.08.005.

35. Pires RN, Monteiro AA, Saldanha GZ, Falci DR, Caurio CFB, Sukiennik TCT, et al. Hypervirulent Clostridium difficile Strain Has Arrived in Brazil. Infect Control Hosp Epidemiol. 2018;39(3):371-3. doi:10.1017/ice.2017.280.

36. Ganc AJ, Ganc RL, Reimão SM, Frisoli Junior A, Pasternak J. Fecal microbiota transplant by push enteroscopy to treat diarrhea caused by Clostridium difficile. Einstein (Sao Paulo). 2015;13(2):338-9. doi:10.1590/S1679-45082015MD3106.

37. Brussels. European Commission Directorate-general for Health and Food Safety Directorate D-Health systems and products D4-Substances of Human Origin and Tobacco Control Competent Authorities on Substances of Human Origin Expert Group (CASoHO E01718) Meeting of the Competent Authorities for Tissues and Cells 3-4 December 2014 Summary Report. 2015.

38. Bakken JS, Borody T, Brandt LJ, Brill JV, Demarco DC, Franzos MA, et al. Treating Clostridium difficile infection with fecal microbiota transplantation. Clin Gastroenterol Hepatol. 2011;9(12):1044-9. doi:10.1016/j.cgh.2011.08.014.

39. Paramsothy S, Borody TJ, Lin E, Finlayson S, Walsh AJ, Samuel D, et al. Donor Recruitment for Fecal Microbiota Transplantation. Inflamm Bowel Dis. 2015;21(7):1600-6. doi:10.1097/MIB.0000000000000405.

40. Relman D, Vender RJ, Rustgi AK, Wang KK, Bousvaros A. Current consensus guidance on donor screening and stool testing for FMT. 2013. Available from: http://www.gastro.org/research/Joint_Society_FMT_Guidance.pdf.

41. The Microbiome Health Research Institute, d.b.a. OpenBiome. Forms \& Guides. [Accessed 24 Mar 2020]. Available at: http://www.openbiome.org.

42. Silva ROS, Vilela EG, Neves MS, Lobato FCF. Evaluation of three enzyme immunoassays and a nucleic acid amplification test for the diagnosis of Clostridium difficile-associated diarrhea at a university hospital in Brazil. Rev. Soc. Bras. Med. Trop. 2014;47(4):447-50. Doi: 10.1590/0037-8682-0100-2014. 
43. Leffler DA, Lamont JT. Clostridium difficile infection. N Engl J Med 2015;372(16):1539-48. doi:10.1056/NEJMra1403772.

44. Charlson ME, Pompei P, Ales KL, MacKenzie CR. A new method of classifying prognostic comorbidity in longitudinal studies: development and validation. J Chronic Dis. 1987;40(5):373-83. doi:10.1016/0021-9681(87)90171-8.

45. Lewis SJ, Heaton KW. Stool form scale as a useful guide to intestinal transit time Scand J Gastroenterol. 1997;32(9):920-4. doi:10.3109/00365529709011203.

46. Kelly CR, Khoruts A, Staley C, Sadowsky MJ, Abd M, Alani M, et al. Effect of Fecal Microbiota Transplantation on Recurrence in Multiply Recurrent Clostridium difficile Infection: A Randomized Trial. Ann Intern Med. 2016;165(9):609-16. doi:10.7326/M16-0271.

47. König J, Siebenhaar A, Högenauer C, Arkkila P, Nieuwdorp M, Norén T, et al. Consensus report: faecal microbiota transfer - clinical applications and procedures. Aliment Pharmacol Ther. 2017;45(2):222-39. doi:10.1111/apt.13868

48. Ma Y, Liu J, Rhodes C, Nie Y, Zhang F. Ethical Issues in Fecal Microbiota Transplantation in Practice. Am J Bioeth. 2017;17(5):34-45. doi:10.1080/15265 61.2017.1299240

49. Alang N, Kelly CR. Weight gain after fecal microbiota transplantation. Open Forum Infect Dis. 2015;2(1):ofv004. Published 2015 Feb 4. doi:10.1093/ofid/ ofv004.

50. Wong SH, Zhao L, Zhang X, Nakatsu G, Han J, Xu W, et al. Gavage of Fecal Samples From Patients With Colorectal Cancer Promotes Intestinal Carcinogenesis in Germ-Free and Conventional Mice. Gastroenterology. 2017;153(6) 1621-33.e6.

51. Koeth RA, Wang Z, Levison BS, Buffa JA, Org E, Sheehy BT, et al. Intestinal microbiota metabolism of L-carnitine, a nutrient in red meat, promotes atherosclerosis. Nat Med. 2013;19(5):576-85. doi:10.1038/nm.3145.

52. Lai CY, Sung J, Cheng F, Tang W, Wong SH, Chan PKS, et al. Systematic review with meta-analysis: review of donor features, procedures and outcomes in 168 clinical studies of faecal microbiota transplantation. Aliment Pharmacol Ther. 2019;49(4):354-63. doi:10.1111/apt.15116.

53. Leis S, Borody TJ, Jiang C, Campbell J. Fecal microbiota transplantation: A "How-To" guide for nurses. Collegian [Internet]. 2015;22(4):445-51. Available from: http://dx.doi.org/10.1016/j.colegn.2014.08.002.

54. Jovel J, Dieleman LA, Kao D, Mason AL, Wine E. The Human Gut Microbiome in Health and Disease. Metagenomics Perspect Methods, Appl. 2018;197-213.

55. Millan B, Laffin M, Madsen K. Fecal Microbiota Transplantation: Beyond Clostridium difficile. Curr Infect Dis Rep. 2017;19(9):31. doi:10.1007/s11908017-0586-5

56. Ridaura VK, Faith JJ, Rey FE, Cheng J, Duncan AE, Kau AL, et al. Gut microbiota from twins discordant for obesity modulate metabolism in mice. Science. 2013;341(6150):1241214. doi:10.1126/science.1241214

57. Hagel S, Fischer A, Ehlermann P, Frank T, Tueffers K, Sturm A, et al. Fecal Microbiota Transplant in Patients With Recurrent Clostridium Difficile Infection. Dtsch Arztebl Int. 2016;113(35-36):583-9. doi:10.3238/arztebl.2016.0583.

58. Decker BK, Lau AF, Dekker JP, Spalding CD, Sinaii N, Conlan S, et al. Healthcare personnel intestinal colonization with multidrug-resistant organisms. Clin Microbiol Infect 2018;24:82.e1-82.e4.

59. Leão-Vasconcelos LS, Lima ABM, Costa DM, Rocha-Vilefort LO, Oliveira ACA, Gonçalves NF, et al. Enterobacteriaceae isolates from the oral cavity of workers in a Brazilian oncology hospital. Rev Inst Med Trop Sao Paulo. 2015;57(2):121-7. doi:10.1590/S0036-46652015000200004.

60. European Centre for Disease Prevention and Control. Antimicrobial resistance surveillance in Europe 2013. Annual Report of the European Antimicrobial Resistance Surveillance Network (EARS-Net). Stockholm: ECDC; 2014

61. Ostholm-Balkhed A, Tarnberg M, Nilsson M, Nilsson LE, Hanberger H, Hällgren A, et al. Travel-associated faecal colonization with ESBL producing Enterobacteriaceae: incidence and risk factors. J Antimicrob Chemother 2013; 68:2144-53.

62. Food and Drug Administration. Information pertaining to additional safety protections regarding use of fecal microbiota for transplantation - screening and testing of stool donors for multi-drug resistant organisms. [Internet]. [Accessed 24 Mar 2020]. Available from: https://www. fda. gov/ vaccines- blood- biologics/ safety- availability- biologics/ information- pertaining- additional- safety- protections- regarding- use- fecal- microbiota- transplantation

63. Burns LJ, Dubois N, Smith MB, Mendolia GM, Burgess J, Edelstein C, at al. Donor recruitment and eligibility for fecal microbiota transplantation: results from an international public stool bank. Gastroenterology. 2015;148(4):S-96-S-97.

64. Riddle MS, Connor BA, Beeching NJ, DuPont HL, Hamer DH, Kozarsky P, et al Guidelines for the prevention and treatment of travelers' diarrhea: a graded expert panel report. J Travel Med. 2017;24(suppl_1):S57-S74. doi:10.1093/jtm/tax026.

65. Hitch G. A Review of Guidelines/Guidance from Various Countries Around the World for the Prevention and Management of Travellers' Diarrhoea: A Pharmacist's Perspective. Pharmacy (Basel). 2019;7(3):107. Published 2019 Aug 4. doi:10.3390/pharmacy7030107.
66. Monira S, Shabnam SA, Alam NH, Endtz HP, Cravioto A, Alam M. 16S rRNA gene-targeted TTGE in determining diversity of gut microbiota during acute diarrhoea and convalescence. J Health Popul Nutr. 2012;30(3):250-6. doi:10.3329/ jhpn.v30i3.12287.

67. Jernberg C, Löfmark S, Edlund C, Jansson JK. Long-term ecological impacts of antibiotic administration on the human intestinal microbiota [published correction appears in ISME J. 2013 Feb;7(2):456]. ISME J. 2007;1(1):56-66. doi:10.1038/ ismej.2007.3.

68. Tleyjeh IM, Bin Abdulhak AA, Riaz M, Alasmari FA, Garbati MA, AlGhamd $\mathrm{M}$, et al. Association between proton pump inhibitor therapy and clostridium difficile infection: a contemporary systematic review and meta-analysis. PLoS One. 2012;7(12):e50836. doi:10.1371/journal.pone.0050836.

69. Lo WK, Chan WW. Proton pump inhibitor use and the risk of small intestinal bacterial overgrowth: a meta-analysis. Clin Gastroenterol Hepatol. 2013;11(5):483-90. doi:10.1016/j.cgh.2012.12.011.

70. Kuschnaroff TM, Berrocal TG, Klautau GB, Chiattone CS, Langhi Jr DM, Souza JF, et al. Prevalência da infecção pelo vírus Epstein-Barr em voluntários doadores de sangue e indivíduos com AIDS na cidade de São Paulo. Arq Med Hosp Fac Cienc Med Santa Casa São Paulo. 2007;52(1):8-13.

71. Lobato-Silva DF. Citomegalovírus: epidemiologia baseada em dados de soroprevalência. Rev Pan-Amaz Saude [Internet]. [cited 2020 May 27]. 2016;7(esp):213-9. Available from: http://scielo.iec.gov.br/scielo.php?script=sci_arttext\&pid=S2176-62232016000500213\&lng=pt. http://dx.doi.org/10.5123/ s2176-62232016000500024.

72. Souza MA, Passos AM, Treitinger A, Spada C. Seroprevalence of cytomegalovirus antibodies in blood donors in southern, Brazil. Rev Soc Bras Med Trop. 2010;43(4):359-61. doi:10.1590/s0037-86822010000400004.

73. Serra FC, Machado J, Nicola MH, Jorge MCAS, Cruz LE, Giordano MV, et al Soroprevalência de citomegalovírus em gestantes brasileiras de classe socioeconômica favorecida. DST J Bras Doenças Sex Transm. 2009;21(1):12-5.

74. Paula FM, Costa-Cruz JM. Epidemiological aspects of strongyloidiasis in Brazil. Parasitology. 2011;138(11):1331-40. doi:10.1017/S003118201100120X.

75. Dreyer G, Fernandes-Silva E, Alves S, Rocha A, Albuquerque R, Addiss D. Patterns of detection of Strongyloides stercoralis in stool specimens: implications for diagnosis and clinical trials. J Clin Microbiol. 1996;34:2569-71.

76. Requena-Méndez A, Chiodini P, Bisoffi Z, Buonfrate D, Gotuzzo E, Muñoz J The laboratory diagnosis and follow up of strongyloidiasis: a systematic review. PLoS Negl Trop Dis. 2013;7(1):e2002. doi:10.1371/journal.pntd.0002002.

77. Buonfrate D, Formenti F, Perandin F, Bisoffi Z. Novel approaches to the diagnosis of Strongyloides stercoralis infection. Clin Microbiol Infect. 2015;21(6):543-52. doi:10.1016/j.cmi.2015.04.001.

78. Jahan N, Khatoon R, Ahmad S. A Comparison of Microscopy and Enzyme Linked Immunosorbent Assay for Diagnosis of Giardia lamblia in Human Faecal Specimens. J Clin Diagn Res. 2014;8(11):DC04-DC6. doi:10.7860/ JCDR/2014/9484.5087.

79. Saidin S, Othman N, Noordin R. Update on laboratory diagnosis of amoebiasis Eur J Clin Microbiol Infect Dis. 2019;38(1):15-38. doi:10.1007/s10096-018-3379-3.

80. Draft guidance for industry: enforcement policy regarding investigational new drug requirements for use of fecal microbiota for transplantation to treat Clostridium difficile infection not responsive to standard therapies. FDA. 2013. Center for Biologics E.

81. Novak-Weekley SM, Marlowe EM, Miller JM, Cumpio J, Nomura JH, Vance $\mathrm{PH}$, et al. Clostridium difficile testing in the clinical laboratory by use of multiple testing algorithms. J Clin Microbiol. 2010;48:889-93. https://doi.org/10.1128/ JCM.01801-09.

82. Terveer EM, Crobach MJT, Sanders IMJG, Vos MC, Verduin CM, Kuijper EJ. Detection of Clostridium difficile in feces of asymptomatic patients admitted to the hospital. J Clin Microbiol. 2017; in press. https://doi.org/10.1128/JCM.01858-16.

83. Terveer EM, van Beurden YH, Goorhuis A, Seegers JFML, Bauer MP, van Nood E, et al. How to: Establish and run a stool bank. Clin Microbiol Infect. 2017;23(12):924-30. doi:10.1016/j.cmi.2017.05.015.

84. Kazerouni A, Burgess J, Burns LJ, Wein LM. Optimal screening and donor management in a public stool bank. Microbiome. 2015;3:75. doi:10.1186/s40168015-0140-3.

85. Rode AA, Bytzer P, Pedersen OB, Engberg J. Establishing a donor stool bank for faecal microbiota transplantation: methods and feasibility. Eur J Clin Microbiol Infect Dis. 2019;38(10):1837-47. doi:10.1007/s10096-019-03615-x.

86. Kassam Z, Dubois N, Ramakrishna B, Ling K, Qazi T, Smith M, et al Donor Screening for Fecal Microbiota Transplantation. N Engl J Med 2019;381(21):2070-2. doi:10.1056/NEJMc1913670.

87. BRASIL. Ministério da Saúde. Gabinete do Ministro. Portaria de consolidação no 4, de 03 de outubro de 2017. Consolidação das normas sobre os sistemas e os subsistemas do Sistema Único de Saúde. Diário Oficial da União, Brasília, DF, 03 out. 2017. Seção 1 . 
88. Edelstein C, Daw JR, Kassam Z. Seeking safe stool: Canada needs a universal donor model. CMAJ. 2016;188(17-18):E431-E432. doi:10.1503/cmaj.150672.

89. Borody TJ. "Flora Power"-- fecal bacteria cure chronic C. difficile diarrhea. Am J Gastroenterol. 2000;95(11):3028-9. doi:10.1111/j.1572-0241.2000.03277.x.

90. Zipursky JS, Sidorsky TI, Freedman CA, Sidorsky MN, Kirkland KB. Patient attitudes toward the use of fecal microbiota transplantation in the treatment of recurrent Clostridium difficile infection. Clin Infect Dis. 2012;55(12):1652-8. doi:10.1093/cid/cis809.

91. Starkey JM, MacPherson JL, Bolgiano DC, Simon ER, Zuck TF, Sayers MH. Markers for transfusion-transmitted disease in different groups of blood donors. JAMA. 1989;262(24):3452-4

92. Kassam Z, Lee CH, Yuan Y, Hunt RH. Fecal microbiota transplantation for Clostridium difficile infection: systematic review and meta-analysis. Am J Gastroenterol. 2013;108(4):500-8. doi:10.1038/ajg.2013.59.

93. Gough E, Shaikh H, Manges AR. Systematic review of intestinal microbiota transplantation (fecal bacteriotherapy) for recurrent Clostridium difficile infection. Clin Infect Dis. 2011;53(10):994-1002. doi:10.1093/cid/cir632.

94. Rebello D, Wang E, Yen E, Lio PA, Kelly CR. Hair Growth in Two Alopecia Patients after Fecal Microbiota Transplant. ACG Case Rep J. 2017;4:e107. doi:10.14309/crj.2017.107.

95. Li YT, Cai HF, Wang ZH, Xu J, Fang JY Systematic review with meta-analysis: long-term outcomes of faecal microbiota transplantation for Clostridium difficile infection. Aliment Pharmacol Ther. 2016;43(4):445-57. doi:10.1111/apt.13492.

96. Lee CH, Steiner T, Petrof EO, Smieja M, Roscoe D, Nematallah A, et al. Frozen vs Fresh Fecal Microbiota Transplantation and Clinical Resolution of Diarrhea in Patients With Recurrent Clostridium difficile Infection: A Randomized Clinical Trial. JAMA. 2016;315(2):142-9. doi:10.1001/jama.2015.18098.

97. Hamilton MJ, Weingarden AR, Sadowsky MJ, Khoruts A. Standardized frozen preparation for transplantation of fecal microbiota for recurrent Clostridium difficile infection. Am J Gastroenterol [Internet]. 2012;107(5):761-7. Available from: http://www.ncbi.nlm.nih.gov/pubmed/22290405\%5Cnhttp://www.nature.com/doifinder/10.1038/ajg.2011.482\%5Cnhttp://www.ncbi.nlm.nih.gov/ pubmed/22290405

98. Kelly CR, Kahn S, Kashyap P, Laine L, Rubin D, Atreja A, et al. Update on Fecal Microbiota Transplantation 2015: Indications, Methodologies, Mechanisms, and Outlook. Gastroenterology. 2015;149(1):223-37. doi:10.1053/j.gastro. 2015.05.008.

99. Youngster I, Sauk J, Pindar C, Wilson RG, Kaplan JL, Smith MB, et al. Fecal microbiota transplant for relapsing Clostridium difficile infection using a frozen inoculum from unrelated donors: a randomized, open-label, controlled pilot study. Clin Infect Dis. 2014;58(11):1515-22. doi:10.1093/cid/ciu135.

100. Jiang ZD, Ajami NJ, Petrosino JF, Jun G, Hanis CL, Shas M, et al. Randomised clinical trial: faecal microbiota transplantation for recurrent Clostridum difficile infection - fresh, or frozen, or lyophilised microbiota from a small pool of healthy donors delivered by colonoscopy. Aliment Pharmacol Ther. 2017;45(7):899-908. doi:10.1111/apt.13969.

101. Camacho-Ortiz A, Gutiérrez-Delgado EM, Garcia-Mazcorro JF, Mendoza-Olazarán S, Martínez-Meléndez A, Palau-Davila L, et al. Randomized clinica trial to evaluate the effect of fecal microbiota transplant for initial Clostridium difficile infection in intestinal microbiome. PLoS One. 2017;12(12):e0189768. doi:10.1371/journal.pone.0189768.

102. Staley C, Hamilton MJ, Vaughn BP, Graiziger CT, Newman KM, Kabage AJ, et al. Successful Resolution of Recurrent Clostridium difficile Infection using Freeze-Dried, Encapsulated Fecal Microbiota; Pragmatic Cohort Study. Am J Gastroenterol. 2017;112(6):940-947. doi:10.1038/ajg.2017.6.

103. Satokari R, Mattila E, Kainulainen V, Arkkila PE. Simple faecal preparation and efficacy of frozen inoculum in faecal microbiota transplantation for recurrent Clostridium difficile infection--an observational cohort study. Aliment Pharmacol Ther. 2015;41(1):46-53. doi:10.1111/apt.13009.

104. Osman M, O'Brien K, Stoltzner Z, Ling K, Koelsch E, Dubois N, et al. Safety and efficacy of fecal microbiota transplantation for recurrent Clostridium difficile infection from an international public stool bank: results from a 2050-patient multicenter cohort. IDWeek; 2016 Oct 26-30; New Orleans. [Internet]. Available from https://idsa.confex.com/idsa/2016/webprogram/Paper59497.html

105. Link A, Lachmund T, Schulz C, Weigt J, Malfertheiner P. Endoscopic peroral jejunal fecal microbiota transplantation. Dig Liver Dis. 2016;48(11):1336-9. doi:10.1016/j.dld.2016.08.110.

106. Chu ND, Smith MB, Perrotta AR, Kassam Z, Alm EJ. Profiling Living Bacteria Informs Preparation of Fecal Microbiota Transplantations. PLoS One. 2017;12(1):e0170922. doi:10.1371/journal.pone.0170922.

107. Ott SJ, Musfeldt M, Timmis KN, Hampe J, Wenderoth DF, Schreiber S. In vitro alterations of intestinal bacterial microbiota in fecal samples during storage. Diagn Microbiol Infect Dis. 2004;50(4):237-45. doi:10.1016/j.diagmicrobio 2004.08.012
108. Mullish BH, Quraishi MN, Segal JP, McCune VL, Baxter, M, Marsden GL, et al. The use of faecal microbiota transplant as treatment for recurrent or refractory Clostridium difficile infection and other potential indications: joint British Society of Gastroenterology (BSG) and Healthcare Infection Society (HIS) guidelines. Gut. 2018;67(11):1920-41. doi:10.1136/gutjnl-2018-316818.

109. Cardona S, Eck A, Cassellas M, Gallart M, Alastrue C, Dore J, et al. Storage conditions of intestinal microbiota matter in metagenomic analysis. BMC Microbiol. 2012;12:158. Published 2012 Jul 30. doi:10.1186/1471-2180-12-158.

110. Carroll IM, Ringel-Kulka T, Siddle JP, Klaenhammer TR, Ringel Y. Characterization of the fecal microbiota using high-throughput sequencing reveals a stable microbial community during storage. PLoS One. 2012;7(10):e46953. doi:10.1371/ journal.pone.0046953

111. Costello SP, Conlon MA, Vuaran MS, Roberts-Thomson IC, Andrews JM. Faecal microbiota transplant for recurrent Clostridium difficile infection using long-term frozen stool is effective: clinical efficacy and bacterial viability data. Aliment Pharmacol Ther. 2015;42(8):1011-8. doi:10.1111/apt.13366.

112. Jiang ZD, Alexander A, Ke S, Valitis EM, Hu S, Li B, et al. Stability and efficacy of frozen and lyophilized fecal microbiota transplant (FMT) product in a mouse model of Clostridium difficile infection (CDI). Anaerobe. 2017;48:110-4. doi:10.1016/j.anaerobe.2017.08.003

113. Bahl MI, Bergström A, Licht TR. Freezing fecal samples prior to DNA extraction affects the Firmicutes to Bacteroidetes ratio determined by downstream quantitative PCR analysis. FEMS Microbiol Lett. 2012;329(2):193-7. doi:10.1111/j.15746968.2012.02523.x.

114. Wang S, Xu M, Wang W, Cao X, Piao M, Khan S, et al. Systematic Review: Adverse Events of Fecal Microbiota Transplantation. PLoS One. 2016;11(8):e0161174. doi:10.1371/journal.pone.0161174.

115. Drekonja D, Reich J, Gezahegn S, Greer N, Shaukat A, McDonald R, et al. Fecal Microbiota Transplantation for Clostridium difficile Infection: A Systematic Review. Ann Intern Med. 2015;162(9):630-8. doi:10.7326/M14-2693.

116. Mccune VL, Quraishi MN, Manzoor S, Moran CE, Banavathi K, Steed H, et al. Results from the first English stool bank using faecal microbiota transplant as a medicinal product for the treatment of Clostridioides difficile infection. EClinicalMedicine [Internet]. [cited 2020 May 1]. 2020;20:100301. Available from: https://doi.org/10.1016/j.eclinm.2020.100301

117. Fischer M, Sipe BW, Rogers NA, Cook GK, Robb BW, Vuppalanchi R, et al. Faecal microbiota transplantation plus selected use of vancomycin for severe-complicated Clostridium difficile infection: description of a protocol with high success rate. Aliment Pharmacol Ther. 2015;42(4):470-6. doi:10.1111/apt.13290.

118. Jalanka J, Salonen A, Salojärvi J, Ritari J, Immonen O, Marciani L, et al. Effects of bowel cleansing on the intestinal microbiota. Gut. 2015;64(10):1562-8. doi:10.1136/gutjnl-2014-307240.

119. Fischer M, Kelly CR, Phelps EL, Wang E, Roach B, Smith JD, et al. Quality of Bowel Preparation does not Affect Outcome of Fecal Microbiota Transplantation for the Therapy Clostridium Difficile Infection. Gastroenterology. 2017 Apr;152(5):S1004-5.

120. Connor A, Tolan D, Hughes S, Carr N, Tomson C. Consensus guidelines for the safe prescription and administration of oral bowel-cleansing agents. Gut. 2012;61(11):1525-32. doi:10.1136/gutjnl-2011-300861.

121. Bauer MP, Notermans DW, van Benthem BH, Brazier JS, Wilcox MH, Rupnik $\mathrm{M}$, et al. Clostridium difficile infection in Europe: a hospital-based survey. Lancet. 2011:377(9759):63-73. doi:10.1016/S0140-6736(10):61266-4

122. Furuya-Kanamori L, Doi SA, Paterson DL, Helms SK, Yakob L, McKenzie SJ, et al. Upper Versus Lower Gastrointestinal Delivery for Transplantation of Fecal Microbiota in Recurrent or Refractory Clostridium difficile Infection: A Collaborative Analysis of Individual Patient Data From 14 Studies. J Clin Gastroenterol. 2017;51(2):145-50. doi:10.1097/MCG.0000000000000511.

123. Vindigni SM, Surawicz CM. Fecal Microbiota Transplantation. Gastroenterol Clin North Am. 2017;46(1):171-85. doi:10.1016/j.gtc.2016.09.012.

124. Rohlke F, Surawicz CM, Stollman N. Fecal flora reconstitution for recurrent Clostridium difficile infection: results and methodology. J Clin Gastroenterol. 2010;44(8):567-70. doi:10.1097/MCG.0b013e3181dadb10.

125. Yoon SS, Brandt LJ. Treatment of refractory/recurrent C. difficile-associated disease by donated stool transplanted via colonoscopy: a case series of 12 patients. J Clin Gastroenterol. 2010;44(8):562-6. doi:10.1097/MCG.0b013e3181 dac035.

26. Kassam Z, Hundal R, Marshall JK, Lee CH. Fecal transplant via retention enema for refractory or recurrent Clostridium difficile infection. Arch Intern Med. 2012;172(2):191-3. doi:10.1001/archinte.172.2.191.

127. Mattila E, Uusitalo-Seppälä R, Wuorela M, Lehtola L, Nurmi H, Ristikankare $\mathrm{M}$, et al. Fecal transplantation, through colonoscopy, is effective therapy for recurrent Clostridium difficile infection. Gastroenterology. 2012;142(3):490-6. doi:10.1053/j.gastro.2011.11.037. 
128. Baxter M, Ahmad T, Colville A, Sheridan R. Fatal Aspiration Pneumonia as a Complication of Fecal Microbiota Transplant. Clin Infect Dis. 2015;61(1):136-7. doi:10.1093/cid/civ247.

129. Solari PR, Fairchild PG, Noa LJ, Wallace MR. Tempered enthusiasm for fecal transplant. Clin Infect Dis. 2014;59(2):319. doi:10.1093/cid/ciu278.

130. Aas J, Gessert CE, Bakken JS. Recurrent Clostridium difficile colitis: case series involving 18 patients treated with donor stool administered via a nasogastric tube. Clin Infect Dis. 2003;36(5):580-5. doi:10.1086/367657.

131. Rossen NG, Fuentes S, van der Spek MJ, Tijssen JG, Hartman JHA, Duflou A, et al. Findings From a Randomized Controlled Trial of Fecal Transplantation for Patients With Ulcerative Colitis. Gastroenterology. 2015;149(1):110-8.e4. doi:10.1053/j.gastro.2015.03.045.

132. Tian H, Ding C, Gong J, Wei Y, McFarland LV, Li N. Freeze-dried, Capsulized Fecal Microbiota Transplantation for Relapsing Clostridium difficile Infection. J Clin Gastroenterol. 2015;49(6):537-8. doi:10.1097/MCG.0000000000000330.

133. Kao D, Roach B, Silva M, Beck P, Rioux K, Kaplan GG, et al. Effect of Ora Capsule- vs Colonoscopy-Delivered Fecal Microbiota Transplantation on Recurrent Clostridium difficile Infection: A Randomized Clinical Trial. JAMA. 2017;318(20):1985-93. doi:10.1001/jama.2017.17077.

134. Sokol H, Galperine T, Kapel N, Bourlioux P, Seksik P, Barbut F, et al. Faecal microbiota transplantation in recurrent Clostridium difficile infection: Recommendations from the French Group of Faecal microbiota Transplantation. Dig Liver Dis. 2016;48(3):242-7. doi:10.1016/j.dld.2015.08.017.

135. Fischer M, Sipe B, Cheng YW, Phelps E, Rogers N, Sagi S, et al. Fecal microbiota transplant in severe and severe-complicated Clostridium difficile: A promising treatment approach. Gut Microbes. 2017;8(3):289-302. doi:10.1080/19490976.2 016.1273998.

136. Shogbesan O, Poudel DR, Victor S, Jehangir A, Fadahunsi O, Shogbesan G, et al. A Systematic Review of the Efficacy and Safety of Fecal Microbiota Transplant for Clostridium difficile Infection in Immunocompromised Patients. Can J Gastroenterol Hepatol. 2018;2018:1394379. doi:10.1155/2018/1394379.

137. Ding X, Li Q, Li P, Zhang T, Cui B, Ji G, et al. Long-Term Safety and Efficacy of Fecal Microbiota Transplant in Active Ulcerative Colitis. Drug Saf. 2019;42(7):869-80. doi:10.1007/s40264-019-00809-2.

138. Food and Drug Administration. Fecal Microbiota for Transplantation: Safety Alert - Risk of Serious Adverse Events Likely Due to Transmission of Pathogenic Organisms. [Internet]. [Accessed 23 Mar 2020]. Available from: https://www.fda. gov/safety/medical-product-safety-information/fecal-microbiota-transplantation-safety-alert-risk-serious-adverse-events-likely-due-transmission

139. Azimirad M, Yadegar A, Asadzadeh Aghdaei H, Kelly CR. Enterotoxigenic Clostridium perfringens Infection as an Adverse Event After Faecal Microbiota Transplantation in Two Patients With Ulcerative Colitis and Recurrent Clostridium difficile Infection: A Neglected Agent in Donor Screening. J Crohns Colitis. 2019;13(7):960-1. doi:10.1093/ecco-jcc/jjz006.
140. Food and Drug Administration. Information pertaining to additional safety protections regarding use of fecal microbiota for transplantation - screening and testing of stool donors for multi-drug resistant organisms. [Internet]. [Accessed 24 Mar 2020]. Available from: available: https://www. fda. gov/ vaccines- bloodbiologics/ safety- availability- biologics/ information- pertaining- additionalsafety- protections- regarding- use- fecal- microbiota- transplantation.

141. Kelly CR, Ihunnah C, Fischer M, Khoruts A, Surawicz C, Afzali A, et al. Fecal microbiota transplant for treatment of Clostridium difficile infection in immunocompromised patients. Am J Gastroenterol. 2014;109(7):1065-71. doi:10.1038/ ajg.2014.133.

142. Frank J, Högenauer C, Gröchenig HP, Hoffmann KM, Reicht G, Wenzl H, et al. Safety of fecal microbiota transplantation in patients with chronic colitis and immunosuppressive treatment. J Crohns Colitis. 2015;9:S245-S246.

143. ClinicalTrials. gov. Fecal microbiota transplant national registry (FMT). [Internet]. [Accessed 23 Mar 2020]. Available: https:// ClinicalTrials. gov/ show/ NCT03325855.

144. Zhang S, Palazuelos-Munoz S, Balsells EM, Nair H, Chit A, Kyaw MH. Cost of hospital management of Clostridium difficile infection in United States-a meta-analysis and modelling study. BMC Infect Dis. 2016;16(1):447. doi:10.1186/ s12879-016-1786-6.

145. Jones AM, Kuijper EJ, Wilcox MH. Clostridium difficile: a European perspective J Infect. 2013;66(2):115-28. doi:10.1016/j.jinf.2012.10.019.

146. Konijeti GG, Sauk J, Shrime MG, Gupta M, Ananthakrishnan AN. Cost-effectiveness of competing strategies for management of recurrent Clostridium difficile infection: a decision analysis. Clin Infect Dis. 2014;58(11):1507-14. doi:10.1093/ cid/ciul28.

147. Chang JY, Antonopoulos DA, Kalra A, Tonelli A, Khalife WT, Schmidt TM, et al. Decreased diversity of the fecal Microbiome in recurrent Clostridium difficile-associated diarrhea. J Infect Dis. 2008;197(3):435-8. doi:10.1086/ 525047.

148. Hamilton MJ, Weingarden AR, Unno T, Khoruts A, Sadowsky MJ. High-throughput DNA sequence analysis reveals stable engraftment of gut microbiota following transplantation of previously frozen fecal bacteria. Gut Microbes. 2013;4(2):125-35. doi:10.4161/gmic.23571.

149. Khoruts A, Dicksved J, Jansson JK, Sadowsky MJ. Changes in the composition of the human fecal microbiome after bacteriotherapy for recurrent Clostridium difficile-associated diarrhea. J Clin Gastroenterol. 2010;44(5):354-60. doi:10.1097/ MCG.0b013e3181c87e02.

150. Li SS, Zhu A, Benes V, Costea PI, Hercog R, Hildebrand F, et al. Durable coexistence of donor and recipient strains after fecal microbiota transplantation. Science. 2016;352(6285):586-9. doi:10.1126/science.aad8852.

151. Park L, Mone A, Price JC, Tzimas D, Hirsh J, Poles MA, et al. Perceptions of fecal microbiota transplantation for Clostridium difficile infection: factors that predict acceptance. Ann Gastroenterol. 2017;30(1):83-8. doi:10.20524/aog.2016.0098. 